\title{
Mechanisms of Stratospheric and Tropospheric Circulation Response to Projected Arctic Sea Ice Loss*
}

\author{
LANTAO SUN \\ Cooperative Institute for Research in Environmental Sciences, University of Colorado Boulder, and \\ NOAA/Earth System Research Laboratory, Boulder, Colorado \\ Clara DESER AND Robert A. TOMAS \\ National Center for Atmospheric Research, ${ }^{+}$Boulder, Colorado
}

(Manuscript received 3 March 2015, in final form 9 July 2015)

\begin{abstract}
The impact of projected Arctic sea ice loss on the atmospheric circulation is investigated using the Whole Atmosphere Community Climate Model (WACCM), a model with a well-resolved stratosphere. Two 160-yr simulations are conducted: one with surface boundary conditions fixed at late twentieth-century values and the other with identical conditions except for Arctic sea ice, which is prescribed at late twenty-first-century values. Their difference isolates the impact of future Arctic sea ice loss upon the atmosphere. The tropospheric circulation response to the imposed ice loss resembles the negative phase of the northern annular mode, with the largest amplitude in winter, while the less well-known stratospheric response transitions from a slight weakening of the polar vortex in winter to a strengthening of the vortex in spring. The lack of a significant winter stratospheric circulation response is shown to be a consequence of largely cancelling effects from sea ice loss in the Atlantic and Pacific sectors, which drive opposite-signed changes in upward wave propagation from the troposphere to the stratosphere. Identical experiments conducted with Community Atmosphere Model, version 4, WACCM's low-top counterpart, show a weaker tropospheric response and a different stratospheric response compared to WACCM. An additional WACCM experiment in which the imposed ice loss is limited to August-November reveals that autumn ice loss weakens the stratospheric polar vortex in January, followed by a small but significant tropospheric response in late winter and early spring that resembles the negative phase of the North Atlantic Oscillation, with attendant surface climate impacts.
\end{abstract}

\section{Introduction}

Arctic sea ice extent is declining at an accelerating pace, and climate models project a seasonally ice-free Arctic Ocean by the middle of this century in response to increasing greenhouse gas $(\mathrm{GHG})$ concentrations

\footnotetext{
* Supplemental information related to this paper is available at the Journals Online website: http://dx.doi.org/10.1175/JCLI-D-150169.s1.

${ }^{+}$The National Center for Atmospheric Research is sponsored by the National Science Foundation.

Corresponding author address: Dr. Lantao Sun, Cooperative Institute for Research in Environmental Sciences, University of Colorado Boulder and NOAA/Earth System Research Laboratory, R/PSD1, 325 Broadway, Boulder, CO 80305.

E-mail: lantao.sun@noaa.gov
}

[see Stroeve et al. (2012), and references therein]. The sea ice loss is expected to have numerous consequences for regional climate, including Arctic amplification (enhanced warming in the Arctic compared to lower latitudes) and increased precipitation at high latitudes (e.g., Screen and Simmonds 2010; Deser et al. 2010). It is also expected to affect the large-scale tropospheric circulation, manifest as the negative phase of the northern annular mode (NAM) (Thompson and Wallace 2000) in winter (see Deser et al. 2010; Butler et al. 2010; Liu et al. 2012; Peings and Magnusdottir 2014; Deser et al. 2015 and references therein). Moreover, recent studies have tried to link diminishing sea ice to enhanced meandering of the tropospheric flow (Francis and Vavrus 2012) and an increase in blocking frequency (Liu et al. 2012), thereby inducing more extreme weather events in midlatitudes. These findings, however, have been challenged by other studies (Barnes 2013; Screen and 
Simmonds 2013; Hassanzadeh et al. 2014; Barnes et al. 2014), and it is still poorly understood whether the proposed mechanisms are viable and whether they are the dominant factors in the tropospheric circulation response to Arctic sea ice loss.

Compared to the troposphere, the impact of Arctic sea ice loss on the stratosphere has received less attention and the findings from different studies are not always consistent. Ideally, if the stratospheric polar vortex is weakened/strengthened due to Arctic sea ice loss, the stratospheric signal could subsequently extend downward and cause a negative/positive NAM response in the troposphere (Baldwin and Dunkerton 2001). This has been found to be the case in some modeling and empirical studies (e.g., Peings and Magnusdottir 2014; Kim et al. 2014; Feldstein and Lee 2014), in which Arctic sea ice loss induces a weakening of the polar vortex in February and a subsequent negative NAM response over the following weeks. However, other modeling studies instead find a strengthening of the polar vortex either in November (Cai et al. 2012) or in March (Scinocca et al. 2009; Screen et al. 2013; Sun et al. 2014) in response to Arctic sea ice loss. These discrepancies highlight the need for further research to understand the impact of Arctic sea ice loss on the stratospheric circulation and the role of the stratosphere in the tropospheric circulation response.

In this paper, we investigate the impact of projected Arctic sea ice loss on the atmospheric circulation by using the National Center for Atmospheric Research (NCAR) Whole Atmosphere Community Climate Model (WACCM), a model with a well-resolved stratosphere. This work is complementary to our previous paper (Sun et al. 2014), which focused solely on the springtime polar stratospheric ozone and circulation responses. Here we emphasize the winter stratospheric and tropospheric circulation responses. As we shall show, the stratospheric circulation response is sensitive to the geographical location of the sea ice loss. Specifically, ice loss in the Atlantic and Pacific sectors has the opposite effect on the stratospheric circulation. This finding may help to reconcile the conflicting results of the modeling studies discussed above, as their region of prescribed ice loss was not always the same.

The simulated tropospheric circulation response to a doubling of $\mathrm{CO}_{2}$ or to North Atlantic sea surface temperature (SST) anomalies associated with the Atlantic multidecadal oscillation (AMO) has been shown to be sensitive to the representation of the stratosphere (Sigmond et al. 2008; Omrani et al. 2014; Peings and Magnusdottir 2015, manuscript submitted to Climate Dyn.). This sensitivity has been attributed to differences in the stratospheric basic states (Sigmond and Scinocca
2010), or to deficiencies in the simulation of stratospheric sudden warmings in low-top models (CharltonPerez et al. 2013; Omrani et al. 2014). To investigate the role of the stratosphere in the tropospheric circulation response to Arctic sea ice loss, we repeat the WACCM sea ice loss experiments with Community Atmosphere Model, version 4 (CAM4), WACCM's low-top counterpart. Previous studies have indicated that the polar vortex is normally too strong in the low-top model due to more wave reflection near the model lid (e.g., Boville 1984; Boville and Cheng 1988; Shaw and Perlwitz 2010) and the downward propagation of stratospheric sudden warmings (SSWs) are substantially different between two configurations of the models (Sassi et al. 2010). It is thus interesting to compare the atmospheric circulation responses to Arctic sea ice loss between WACCM and CAM4: are the stratospheric responses different, and does this affect the tropospheric response?

Last, observational studies have found a statistical connection between Arctic sea ice in early autumn when the ice extent is at a minimum, and a negative phase of the NAM in the following winter (Francis et al. 2009; Wu and Zhang 2010). These empirical findings do not necessary imply causality, however. Here we test whether autumn sea ice loss has an impact on the winter and spring atmospheric circulation by conducting an additional WACCM experiment in which the ice loss is confined to August-November. This experiment, in conjunction with the full sea ice loss experiment, allows us to evaluate the relative roles of autumn versus contemporaneous sea ice loss on the winter and spring atmospheric circulation responses.

The rest of this paper is organized into four sections. Section 2 contains a description of the models and experiments. Section 3 presents the atmospheric circulation response to Arctic sea ice loss in the various experiments, including the mechanism of the stratospheric circulation response, comparison between WACCM and CAM4, and the role of autumn versus winter and spring sea ice loss. The discussion and conclusions follow in section 4 .

\section{Models and experimental design}

\section{a. Models}

We use WACCM version 4, a high-top model with a horizontal resolution of $1.9^{\circ}$ latitude and $2.5^{\circ}$ longitude, and 66 vertical levels extending from the surface to approximately $140 \mathrm{~km}$. In addition to enhanced vertical resolution in the stratosphere and mesosphere, WACCM incorporates an interactive stratospheric chemistry package and special gravity wave parameterizations. 
These additional features make this model a better tool for studying the stratospheric response than more commonly used low-top models. Details of the model formulation and WACCM's twentieth- century transient simulation are documented in Marsh et al. (2013).

We also make use of CAM4, a "low-top" model with horizontal resolution of $1.9^{\circ}$ latitude and $2.5^{\circ}$ longitude, and 26 vertical levels extending from the surface to $3.5 \mathrm{hPa}$. Stratospheric ozone is prescribed since there is no interactive chemistry. The surface wind stress parameterization in CAM4 also partly differs from WACCM in that there is no turbulent mountain stress (Marsh et al. 2013). Details of the model can be found in Neale et al. (2013).

\section{b. Experiments}

To investigate the impact of future sea ice loss upon the stratosphere, we have conducted a pair of 161-yr experiments. The control experiment (hereafter denoted $\left.\mathrm{ICE}_{\text {control }}\right)$ is specified with a repeating seasonal cycle of sea ice concentration (SIC) and SST, averaged over the period 1980-99, obtained from the average of a three-member ensemble of twentieth-century simulations with the corresponding fully coupled version of WACCM (Marsh et al. 2013). The perturbation experiment (hereafter denoted $\mathrm{ICE}_{\text {total }}$ ) is specified with a repeating seasonal cycle of Arctic SIC averaged over the period 2080-99, obtained from the single available twenty-first-century simulation of the fully coupled version of WACCM, forced by Representative Concentration Pathway (RCP) 8.5 (corresponding to a radiative forcing level of approximately $8.5 \mathrm{~W} \mathrm{~m}^{-2}$ by 2100). In both experiments, the radiative forcings and ozone-depleting substances (ODS) are fixed at the year 2000 so as to isolate the impact of Arctic sea ice loss. Note that we do not change SIC in the Antarctic. Following convention (e.g., Peings and Magnusdottir 2014), sea ice thickness is specified to be $2 \mathrm{~m}$ in the Arctic and $1 \mathrm{~m}$ in the Antarctic.

The SSTs in the perturbation experiment are the same as those in the control experiment except in areas where the fractional ice cover in the late twenty-first century is less than that in the late twentieth century. In these cases, the SSTs are set to their 2080-99 values from the WACCM RCP8.5 run. This approach takes into account not only the sea ice loss, but also the local warming of the sea surface that occurs in association with the ice loss (see also Screen et al. 2013; Deser et al. 2015). Differencing the perturbation and control experiments yields the impact of future Arctic sea ice loss and associated local SST warming on the atmosphere.

To address the impact of different geographical locations of Arctic sea ice loss, we perform two additional 161-yr experiments. In the first one, we prescribe future sea ice (and local SST) conditions inside the Arctic Circle (i.e., poleward of $66.6^{\circ} \mathrm{N}$ ), but present-day sea ice (and local SST) conditions elsewhere. Since most of the sea ice loss within the Arctic Circle occurs in the Barents-Kara Sea in winter and spring (Fig. 1c), this

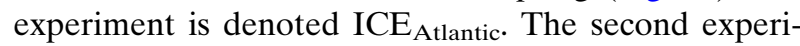
ment is similar except that only future ice and local SST conditions outside the Arctic Circle are prescribed, with the ice conditions inside the Arctic Circle and nonlocal SST the same as those in $\mathrm{ICE}_{\text {control }}$. This experiment is referred to as $\mathrm{ICE}_{\text {Pacific }}$ due to the fact that most of ice loss outside of the Arctic Circle is distributed in the Pacific in winter and spring (Fig. 1c). Summing the sea ice loss in ICE $\mathrm{Itlantic}_{\text {and ICE }}$ Pacific yields the sea ice loss in $\mathrm{ICE}_{\text {total }}$.

In addition to the WACCM experiments, we have conducted analogous simulations with CAM4. In particular, we have carried out two 161-yr experiments in which the same sea ice and SST distributions from the WACCM ICE control $_{\text {and }}$ ICE $_{\text {total }}$ simulations are prescribed to CAM4 (referred to as ICE $_{\text {control_CAM4 } 4}$ and $\mathrm{ICE}_{\text {total_CAM4, }}$, respectively).

Last, to assess the role of autumn sea ice loss in the winter and spring atmospheric circulation responses, we perform an additional WACCM experiment similar to $\mathrm{ICE}_{\text {total }}$ except that the sea ice loss is confined to August-November (denoted ICE autumn $_{\text {). }}$.

Table 1 provides a full list of all the experiments and their boundary conditions. In the rest of this paper, we shall refer to the difference between $\mathrm{ICE}_{\text {total }}$ and $\mathrm{ICE}_{\text {control }}$ as $\triangle \mathrm{ICE}_{\text {total }}$. Similar terminologies are used for $\Delta \mathrm{ICE}_{\text {Atlantic }}, \Delta \mathrm{ICE}_{\text {Pacific }}, \Delta \mathrm{ICE}_{\text {autumn }}$, and $\Delta \mathrm{ICE}_{\text {total_CAM4. }}$ A Student's $t$ test is used to estimate the statistical significance of the responses. We discard the first year of each 161-yr simulation from our analysis.

\section{Results}

\section{a. Seasonal cycle of projected Arctic sea ice loss and surface energy flux response}

Figures 1a-c shows the seasonal cycle of SIC from the fully coupled WACCM simulations in the late twentieth century (1980-99) and late twenty-first century (2080 99) in fully coupled WACCM, and their difference. WACCM's simulation of the present-day sea ice distribution is in good agreement with observations (e.g., Stroeve et al. 2012), although there is a slight overestimation of the concentrations in the Pacific marginal ice zone in winter and spring (see Fig. S1 in the supplemental material). In the late twenty-first century, WACCM's projected sea ice cover contracts poleward 
Sea Ice Concentration \& Surface Energy Flux Response
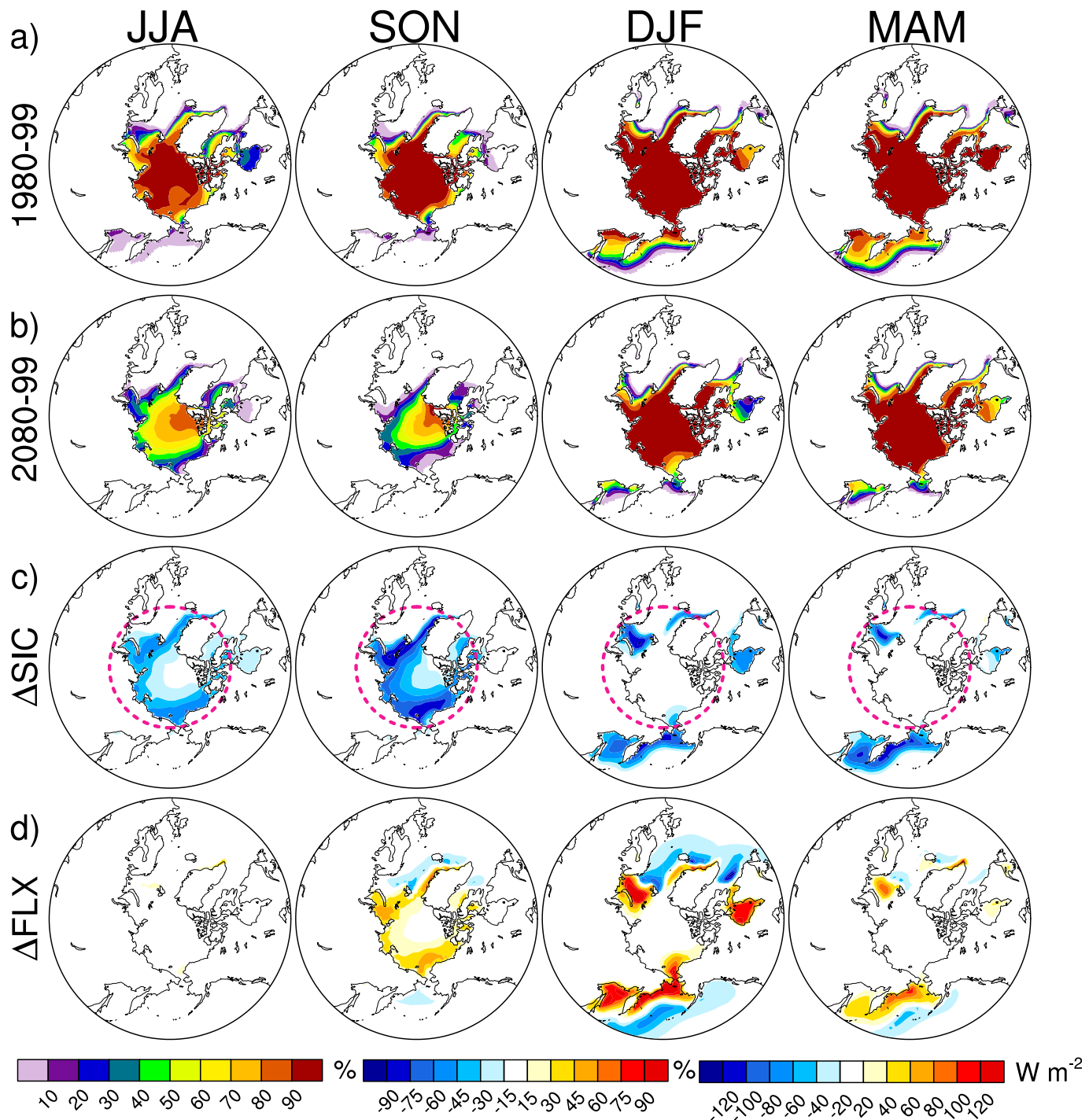

FIG. 1. Seasonal cycle of sea ice concentration (SIC; \%) averaged over the (a) late twentieth century (1980-99), (b) late twenty-first century (2080-99), and (c) their difference. In (a) and (b) the values are obtained from the fully coupled WACCM historical run and RCP8.5 run, respectively. The dashed circle in (c) denotes the Arctic Circle $\left(66.6^{\circ} \mathrm{N}\right)$. (d) Surface heat flux $\left(\mathrm{W} \mathrm{m}^{-2}\right)$ response (positive upward) in $\Delta \mathrm{ICE}_{\text {total }}$, based on the sum of the turbulent and longwave radiative fluxes.

year-round relative to the late twentieth century. In late summer and early fall, there is substantial SIC reduction within the central Arctic. In winter and spring, the area of the Arctic ice loss is smaller, and distributed in the marginal ice zones (e.g., Bering Sea, Sea of Okhotsk, Barents-Kara Sea, and Hudson Bay).

The sea ice loss affects the atmosphere via changes in net upward surface energy flux (Fig. 1d). The net surface flux is, primarily in the form of turbulent fluxes with a smaller contribution from longwave radiative fluxes, consistent with previous studies (e.g., Deser et al. 2010; Peings and Magnusdottir 2014; Deser et al. 2015). The magnitude of the surface energy flux response varies by season, with the smallest values in summer $\left(<10 \mathrm{~W} \mathrm{~m}^{-2}\right)$ and the largest values in winter (up to $250 \mathrm{~W} \mathrm{~m}^{-2}$ ). The heat flux is upward in the regions of sea ice loss and downward in areas directly to the south. The increase in upward heat flux is associated with the increase in surface temperature due to sea ice melt and local SST warming. To the south, the surface atmosphere is warmed by thermal advection from the ice loss region, while the SST is fixed by 
TABLE 1. Details of the model experiments. For reference, $\Delta \mathrm{ICE}_{\text {total }}=\mathrm{ICE}_{\text {total }}-\mathrm{ICE}_{\mathrm{control}} ; \Delta \mathrm{ICE}_{\mathrm{Atlantic}}=\mathrm{ICE}_{\mathrm{Atlantic}}-\mathrm{ICE}_{\mathrm{control}}$; $\Delta \mathrm{ICE}_{\text {Pacific }}=\mathrm{ICE}_{\text {Pacific }}-\mathrm{ICE}_{\text {control }} ; \Delta \mathrm{ICE}_{\text {autumn }}=\mathrm{ICE}_{\text {autumn }}-\mathrm{ICE}_{\text {control }} ; \Delta \mathrm{ICE}_{\text {total } \_C A M 4}=\mathrm{ICE}_{\text {total } \_C A M 4}-\mathrm{ICE}_{\text {control_CAM4 }}$. In all experiments, the radiative forcings and ozone conditions are fixed at year 2000. Each experiment is run for $161 \mathrm{yr}$ with the first year discarded from the analysis.

\begin{tabular}{lcl}
\hline \hline \multicolumn{1}{c}{ Expt name } & Model configuration & \multicolumn{1}{c}{ Sea ice concentration (SIC) and local SST conditions } \\
\hline ICE $_{\text {control }}$ & WACCM & $1980-99$ average from the fully coupled WACCM historical run \\
ICE $_{\text {total }}$ & WACCM & $2080-99$ average from the fully coupled WACCM RCP8.5 run \\
ICE $_{\text {Atlantic }}$ & WACCM & As in ICE total but only inside the Arctic Circle \\
ICE $_{\text {Pacific }}$ & WACCM & As in ICE total $_{\text {but only outside the Arctic Circle }}$ \\
ICE $_{\text {Autumn }}$ & WACCM & As in ICE total but only from Aug to Nov \\
ICE $_{\text {control_CAM4 }}$ & CAM4 & As in ICE \\
ICE $_{\text {total_CAM4 }}$ & CAM4 & As in ICE \\
\hline
\end{tabular}

experimental design: this leads to a downward flux response.

Figure 2 summarizes the monthly changes of sea ice area (gray bars) between the late twentieth and late twenty-first century, and the Arctic surface energy flux response (solid black curve) in $\Delta \mathrm{ICE}_{\text {total }}$. The largest sea ice loss occurs in August-October $\left(\sim 6 \times 10^{6} \mathrm{~km}^{2}\right)$ and the smallest sea ice loss occurs in March-June $(\sim 3 \times$ $10^{6} \mathrm{~km}^{2}$ ). In contrast, the net surface energy flux response exhibits a pronounced seasonal cycle, with the maximum values in winter $\left(\sim 40 \mathrm{~W} \mathrm{~m}^{-2}\right.$ in DecemberJanuary) and the minimum values in summer $\left(\sim 5 \mathrm{~W} \mathrm{~m}^{-2}\right.$ in June-August). Since sea ice affects the atmosphere via surface energy fluxes, the delay between the maximum ice loss and the peak surface energy flux response has implications for the timing of the atmospheric circulation response (Deser et al. 2010). Specifically, as we shall show, the impact of Arctic sea loss on atmospheric circulation is largest in the winter even though ice loss peaks in the fall.

\section{b. Seasonal cycle of atmospheric circulation response}

Figure 3 shows the seasonal cycle of zonal-mean zonal wind response (shading) in $\triangle \mathrm{ICE}_{\text {total }}$, superimposed on the control run climatology (contours). There is a pronounced seasonal cycle of the zonal wind response in the troposphere. The response peaks in winter, coinciding with the largest surface energy flux response, and is smallest in summer, also consistent with the minimum of the surface energy flux response. The response pattern is characterized by a statistically significant meridional dipole in middle latitudes, with reduced westerlies in the latitude band $50^{\circ}-70^{\circ} \mathrm{N}$ and enhanced westerlies in the band $30^{\circ}-40^{\circ} \mathrm{N}$. This structure projects well onto the negative phase of the NAM (Thompson and Wallace 2000). In summer, there is a small positive zonal mean zonal wind response north of $80^{\circ} \mathrm{N}$, likely induced by the increase in meridional temperature gradient due to sea ice loss around the Arctic Circle.
In contrast to the tropospheric circulation response, the stratospheric circulation response varies between winter and spring. In particular, the polar vortex weakens in winter but strengthens in spring. However, the stratospheric response in winter (spring) is small and only statistically significant in the lower (upper) stratosphere below (above) $50 \mathrm{hPa}$. The strengthening of the polar vortex in spring is accompanied by ozone reduction and stratospheric cooling, in association with a decrease in the Brewer-Dobson circulation due to less upward propagation from the troposphere to the stratosphere (Scinocca et al. 2009; Sun et al. 2014). Hereafter, our main focus will be on the wintertime [December-February (DJF)] circulation response.

\section{c. Sensitivity to geographical location of ice loss}

Some studies highlight the impact of sea ice loss in particular regions, for example, the Barents and Kara Seas (Honda et al. 2009; Kim et al. 2014; Nakamura et al. 2015), while others consider the full geographical pattern of Arctic sea ice loss (Scinocca et al. 2009; Deser et al. 2010; Cai et al. 2012; Screen et al. 2013; Peings and

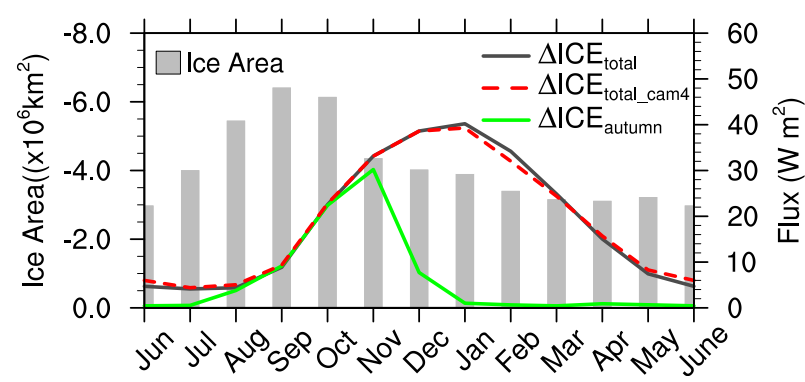

FIG. 2. Seasonal cycle of late twenty-first-century (2080-99) minus late twentieth-century (1980-99) sea ice area (gray bars; $\left.10^{6} \mathrm{~km}^{2}\right)$, and Arctic net surface energy flux $\left(\mathrm{W} \mathrm{m}^{-2}\right)$ response in $\Delta \mathrm{ICE}_{\text {total }}$ (solid black curve), $\Delta \mathrm{ICE}_{\text {autumn }}$ (solid green curve), and $\Delta \mathrm{ICE}_{\text {total_cam4 }}$ (dashed red curve). Note the inverted scale for sea ice area. Sea ice area is calculated by multiplying the ice fraction to the area for each grid box, and summing over the Northern Hemisphere. Surface energy flux includes the turbulent heat flux (latent and sensible heat flux) and longwave radiative flux. 


\section{$[U]$ in WACCM $\left(\triangle \mathrm{ICE}_{\text {total }}\right)$}

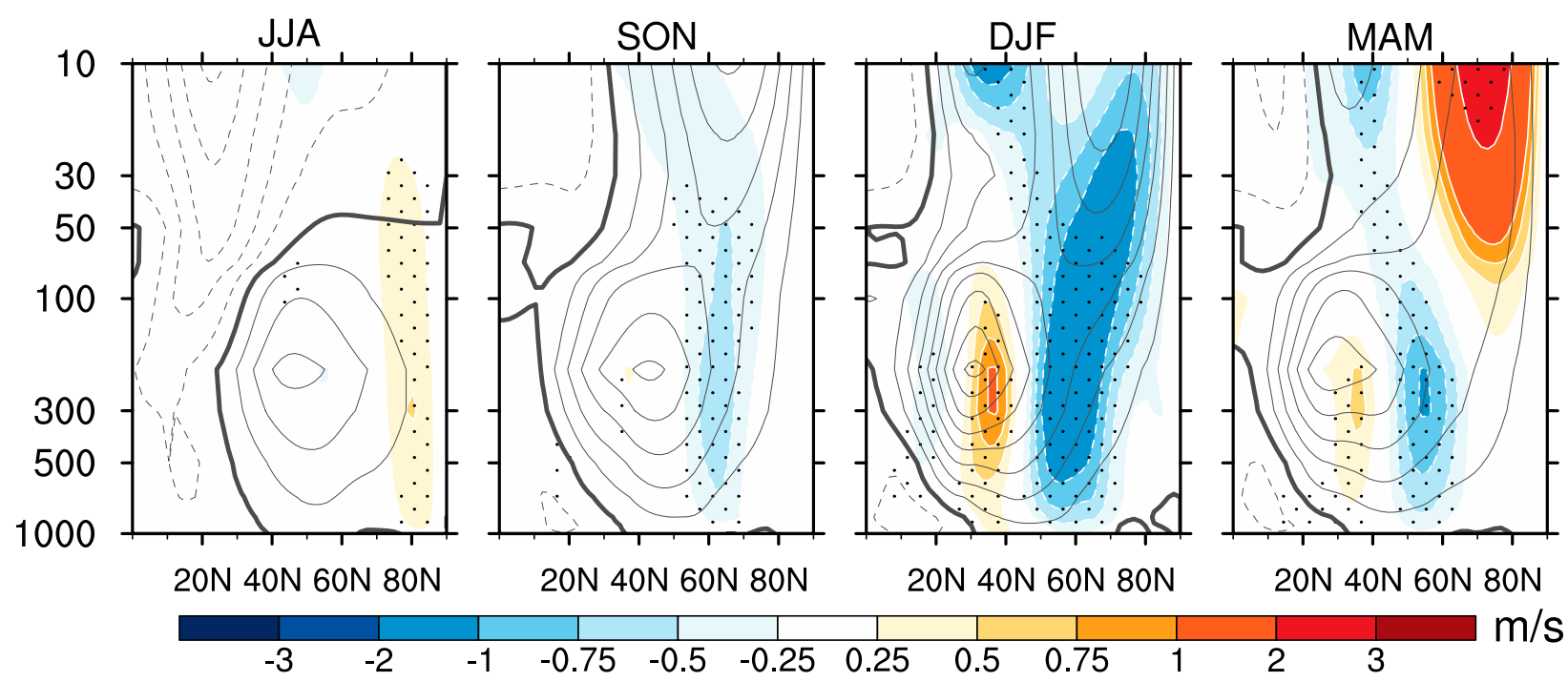

FIG. 3. Zonal-mean zonal wind response (shading) in $\Delta \mathrm{ICE}_{\text {total }}$, superimposed upon the zonal-mean zonal wind climatology from the control run (contours; contour interval of $5 \mathrm{~m} \mathrm{~s}^{-1}$ ) for each season. Stippling indicates that the response is statistically significant at the $95 \%$ confidence level based on a two-sided Student's $t$ test.

Magnusdottir 2014). It is thus of interest to see how much different geographical locations of sea ice loss contribute to the atmospheric circulation response in $\Delta \mathrm{ICE}_{\text {total }}$.

Figure 4 shows the zonal-mean zonal wind response in $\Delta \mathrm{ICE}_{\text {Atlantic }}$ and $\triangle \mathrm{ICE}_{\text {Pacific }}$ during DJF. The opposing sign of the stratospheric responses is striking: a robust weakening of the polar vortex in $\triangle \mathrm{ICE}_{\mathrm{Atlantic}}$ and a robust strengthening in $\triangle \mathrm{ICE}_{\text {Pacific }}$. Thus, the weakly negative and statistically insignificant response of the stratospheric polar vortex in $\Delta \mathrm{ICE}_{\text {total }}$ is a result of largely cancelling effects from the two regions of ice loss. In the troposphere, $\triangle \mathrm{ICE}_{\mathrm{Atlantic}}$ shows a similar meridional dipole response as $\Delta \mathrm{ICE}_{\text {total }}$, albeit displaced about $5^{\circ}$ poleward, while $\triangle \mathrm{ICE}_{\text {Pacific }}$ shows only a weak reduction at the poleward edge of the westerlies.

\section{d. Mechanism of the winter stratospheric response}

Here we investigate the mechanisms of the opposing stratospheric responses in $\Delta \mathrm{ICE}_{\text {Atlantic }}$ and $\Delta \mathrm{ICE}_{\text {Pacific }}$. Figure 5a shows the evolution of the eddy heat flux response $\left(\left[v^{*} T^{*}\right]_{a}\right)$ at $100 \mathrm{hPa}$ from December to May, as an indicator of upward planetary wave propagation from the troposphere to the stratosphere (Charney and Drazin 1961; Eliassen and Palm 1961; Polvani and Waugh 2004). In $\Delta \mathrm{ICE}_{\text {Atlantic, }}$ statistically significant positive anomalies appear in the latitude band $50^{\circ}-80^{\circ} \mathrm{N}$ in December and January, implying more upward wave propagation into the stratosphere in response to sea ice loss in the Barents-Kara Sea. In $\Delta \mathrm{ICE}_{\text {Pacific }}$, by contrast, strong negative anomalies appear over the polar cap (poleward of $60^{\circ} \mathrm{N}$ ) in December, indicating that upward wave propagation has been suppressed as a result of ice loss in the northwestern Pacific. Further analysis of the distribution of eddy heat flux also confirms that these negative anomalies in $\triangle \mathrm{ICE}_{\text {Pacific }}$ mainly come from the suppression of wave activity instead of an increase in magnitude of the total negative heat flux (not shown). There is also a second period of negative anomalies in the polar cap in March, with a smaller magnitude but statistically significant. This also appears in $\Delta \mathrm{ICE}_{\text {total }}$ (not shown), and is responsible for the stratospheric circulation changes in spring (Sun et al. 2014).

Figure 5b shows the Eliassen-Palm (E-P) flux vector and $\mathrm{E}-\mathrm{P}$ divergence response in December and January in $\triangle \mathrm{ICE}_{\text {Atlantic }}$ and $\triangle \mathrm{ICE}_{\text {Pacific }}$. The E-P flux vector is used to characterize the meridional and vertical wave propagation, and E-P divergence indicates the stratospheric wave dissipation. In $\Delta \mathrm{ICE}_{\text {Atlantic }}$, there is enhanced upward wave propagation into the stratosphere whereupon the waves break, resulting in enhanced stratospheric wave dissipation (negative E-P divergence anomalies). In the same way, less upward propagation in $\Delta \mathrm{ICE}_{\text {Pacific }}$ causes less stratospheric dissipation (positive anomalies). Since wave dissipation is responsible for decelerating the westerly winds, their changes can explain the weakening of the polar vortex in $\triangle \mathrm{ICE}_{\text {Atlantic }}$ and strengthening of the polar vortex in $\triangle \mathrm{ICE}_{\text {Pacific }}$.

To further explore why the upward wave propagation responses in $\triangle \mathrm{ICE}_{\mathrm{Atlantic}}$ and $\Delta \mathrm{ICE}_{\text {Pacific }}$ are opposite, 


\section{[U] in DJF}

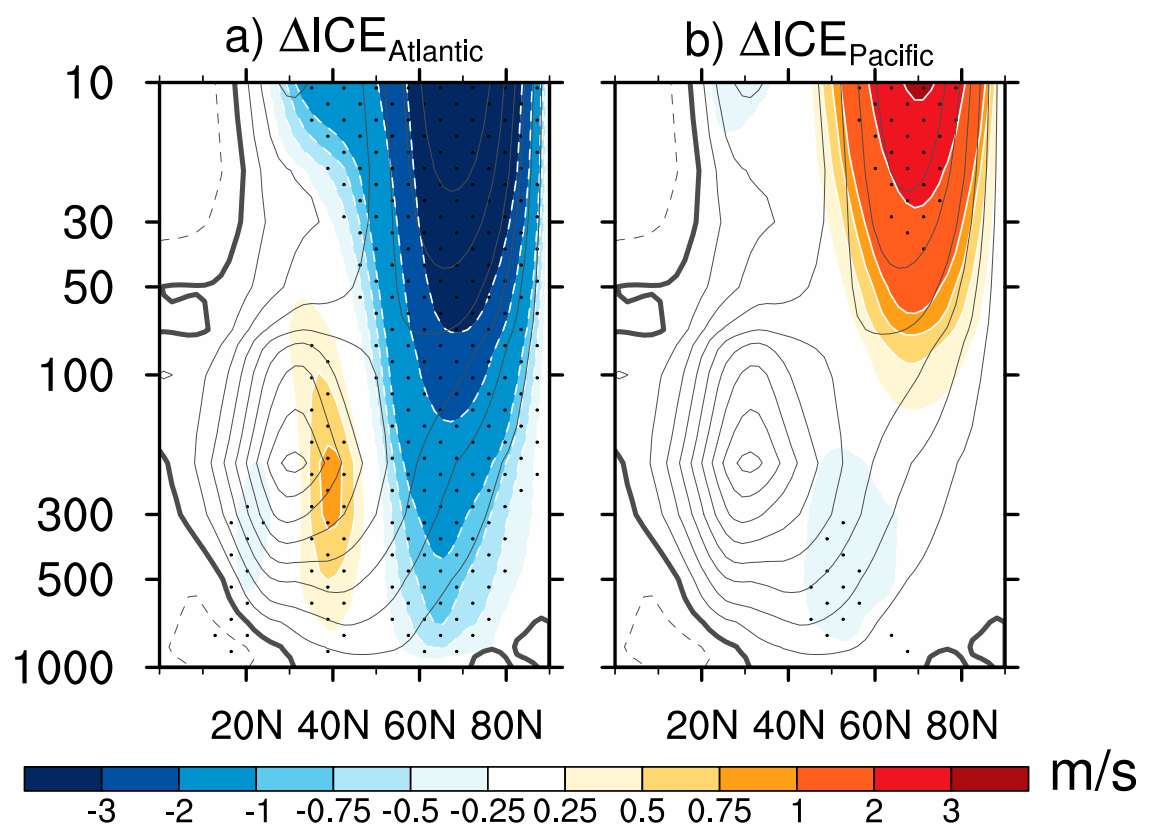

FIG. 4. Winter (DJF) zonal-mean zonal wind response (shading) in (a) $\Delta \mathrm{ICE}_{\mathrm{Atlantic}}$ and (b) $\triangle \mathrm{ICE}_{\text {Pacific }}$, superimposed on the climatology from the control run (contours; contour interval of $5 \mathrm{~m} \mathrm{~s}^{-1}$ ). Stippling indicates that the response is statistically significant at the $95 \%$ confidence level.

we decompose the eddy heat flux into linear and nonlinear components following Nishii et al. (2009):

$$
\left[v^{*} T^{*}\right]_{a}=\left[v_{c}^{*} T_{a}^{*}\right]+\left[v_{a}^{*} T_{c}^{*}\right]+\left[v_{a}^{*} T_{a}^{*}\right]_{a},
$$

where $\left[v^{*} T^{*}\right]_{a}$ is the total eddy heat flux response and the bracket and asterisk indicate the zonal mean and zonal deviation, respectively, and the subscripts $\mathrm{c}$ and a refer to the climatology and anomaly, respectively. The first two terms on the right-hand side of (1) indicate linear interference between the forced response and the climatological planetary waves; the third term is their nonlinear interaction.

Figure 6 shows the total eddy heat flux response in December-January, and its linear and nonlinear components in $\triangle \mathrm{ICE}_{\text {Atlantic }}$ and $\triangle \mathrm{ICE}_{\text {Pacific }}$. The anomalies are generally of the same sign throughout the stratosphere and troposphere. Near the surface, positive anomalies appear over the polar cap in $\triangle \mathrm{ICE}_{\mathrm{Atlantic}}$, and negative anomalies are distributed in the latitude band $40^{\circ}-60^{\circ} \mathrm{N}$ in $\triangle \mathrm{ICE}_{\text {Pacific. }}$ They both coincide with the latitude band of sea ice loss, implying that the stratospheric responses indeed stem from the impact of Arctic sea ice loss instead of internal vacillations. The total eddy heat flux response is dominated by the linear component for both experiments. Moreover, almost all of the eddy heat flux response comes from zonal wavenumber 1 (Fig. 6). Therefore, in our simulations the linear interference between forced and climatological wavenumber 1 appears to explain the changes in upward wave propagation from the troposphere to the stratosphere. Next we address why wave- 1 linear interference is opposite in $\triangle \mathrm{ICE}_{\mathrm{Atlantic}}$ and $\Delta \mathrm{ICE}_{\text {Pacific }}$, and how this affects upward wave propagation.

Linear wave interference theory has been used to explain tropospheric precursors to stratospheric extreme events such as sudden warmings (e.g., Nishii et al. 2009; Garfinkel et al. 2010; Fletcher and Kushner 2011; Smith and Kushner 2012). According to this theory, if the forced response is in phase (out of phase) with the climatological planetary waves in the troposphere, upward wave propagation from the troposphere to the stratosphere will be enhanced (suppressed). Sun et al. (2014) showed that linear wave interference theory explains the springtime strengthening of the polar vortex in response to Arctic sea ice loss; here we investigate whether it also works for the winter response.

Figure 7 shows the December-January geopotential height response (shading) at 30 and $300 \mathrm{hPa}$ in $\Delta \mathrm{ICE}_{\text {Atlantic }}$ and $\Delta \mathrm{ICE}_{\text {Pacific. }}$. For the purpose of linear wave interference analysis, we also superimpose the climatological zonal wavenumber 1 (contours). At 
a) $\left[\mathrm{v}^{\prime} \mathrm{T}^{\prime}\right]$ at $100 \mathrm{hPa}$
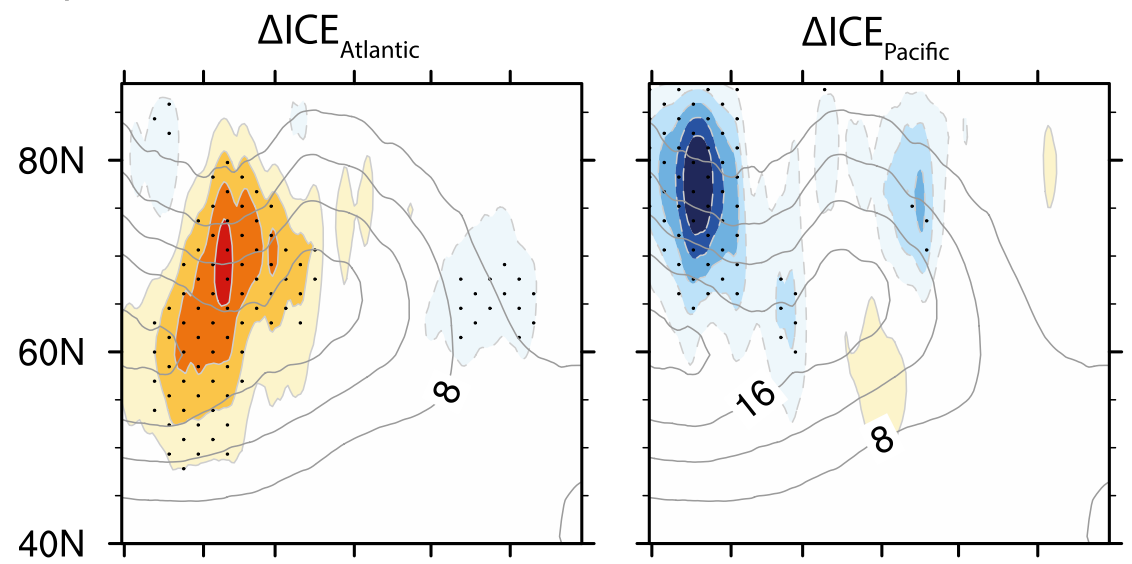

Dec Jan Feb Mar Apr May Dec Jan Feb Mar Apr May

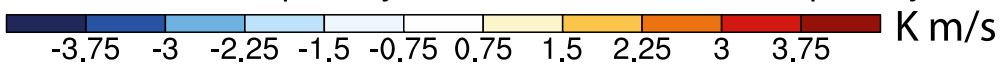

b) E-P flux in Dec-Jan

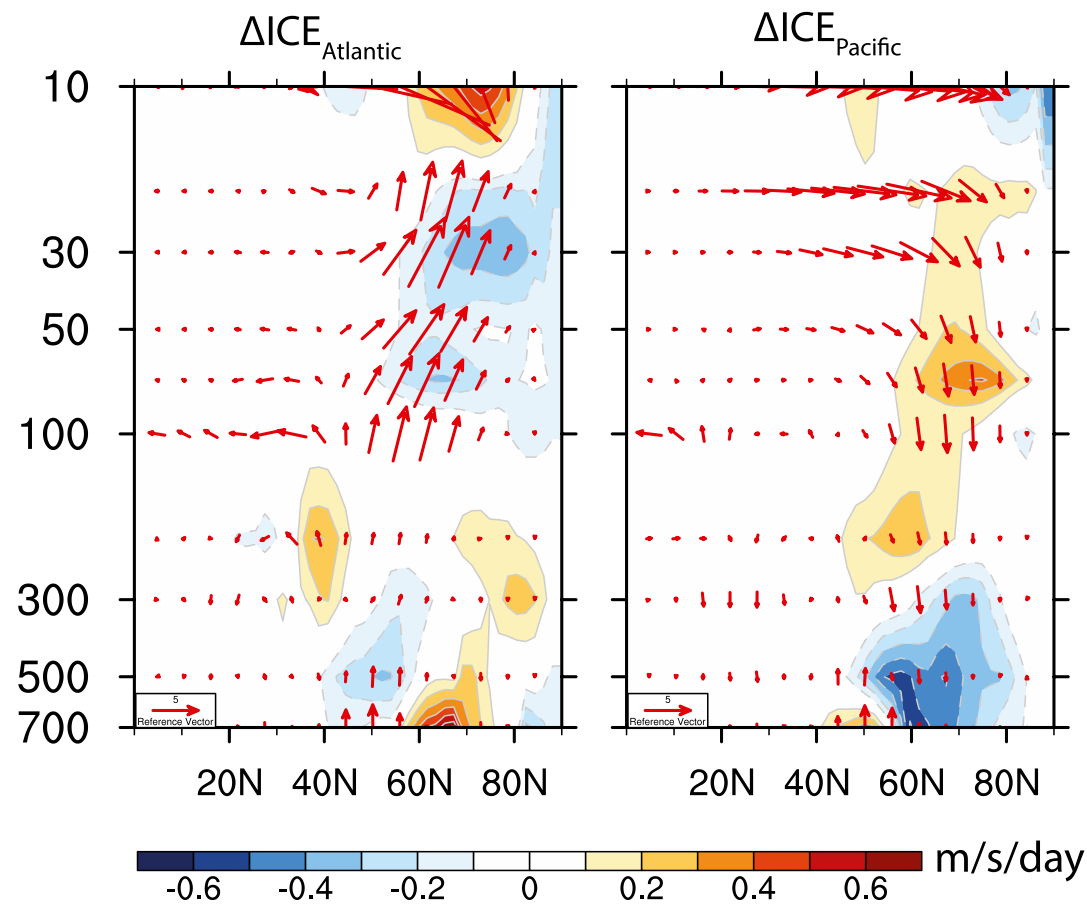

FIG. 5. (a) Seasonal evolution of the zonal-mean eddy heat flux response at $100 \mathrm{hPa}$ (color shading) in $\triangle \mathrm{ICE}_{\text {Atlantic }}$ and $\Delta \mathrm{ICE}_{\text {Pacific }}$, superimposed on the climatology from the control run (contours; contour interval of $4 \mathrm{~K} \mathrm{~m} \mathrm{~s}^{-1}$ ). The horizontal tick marks denote the first day of each month. Stippling indicates that the response is statistically significant at the $95 \%$ confidence level. (b) Response of the Eliassen-Palm (E-P) vector and E-P divergence (color shading)

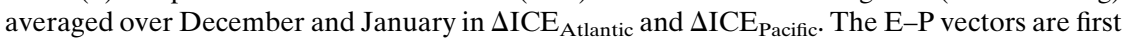
divided by the square root of (1000/pressure) (Taguchi and Hartmann 2006), and then multiplied by a scale factor of 3 above $100 \mathrm{hPa}$ to enhance the small vectors in the stratosphere.

$300 \mathrm{hPa}$, the response in $\Delta \mathrm{ICE}_{\text {Atlantic }}$ is characterized by a positive geopotential height anomaly centered in the Barents-Kara Sea, where sea ice loss resides (crosshatches), and negative anomalies in the Pacific and Atlantic. A similar pattern has been shown in previous studies [e.g., Fig. $2 \mathrm{~b}$ and $3 \mathrm{~b}$ in Kim et al. (2014)]. In the region of sea ice loss, the positive anomaly can be understood as the direct linear 


\section{a) $\triangle$ ICE $_{\text {Atlantic }}$ eddy heat flux}
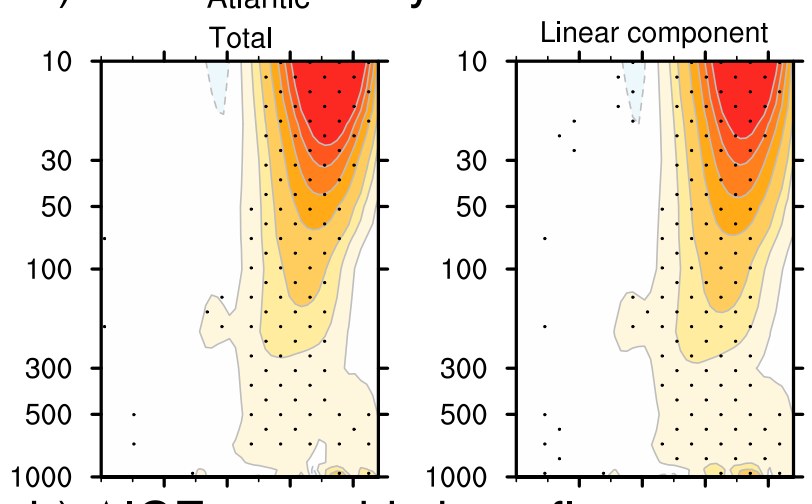

b) $\triangle \mathrm{ICE}_{\text {Pacific }}$ eddy heat flux

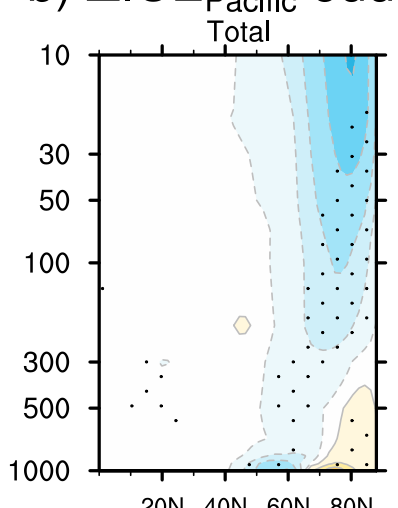

$20 \mathrm{~N} 40 \mathrm{~N} 60 \mathrm{~N} 80 \mathrm{~N}$

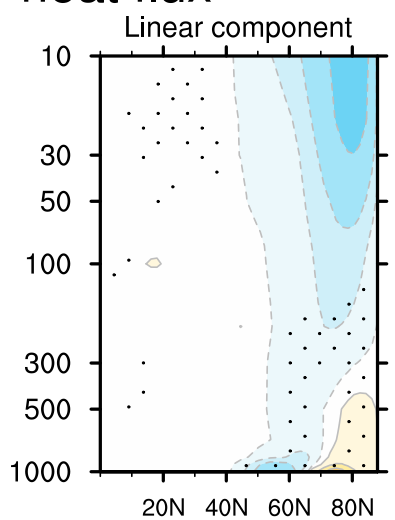

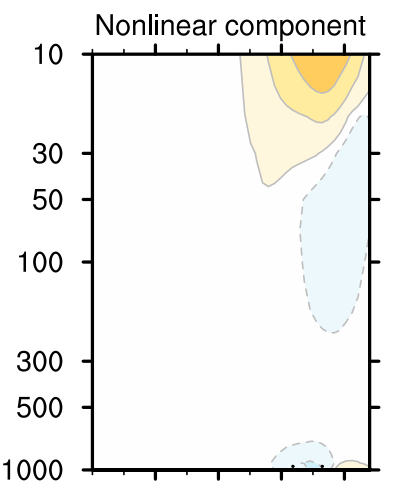
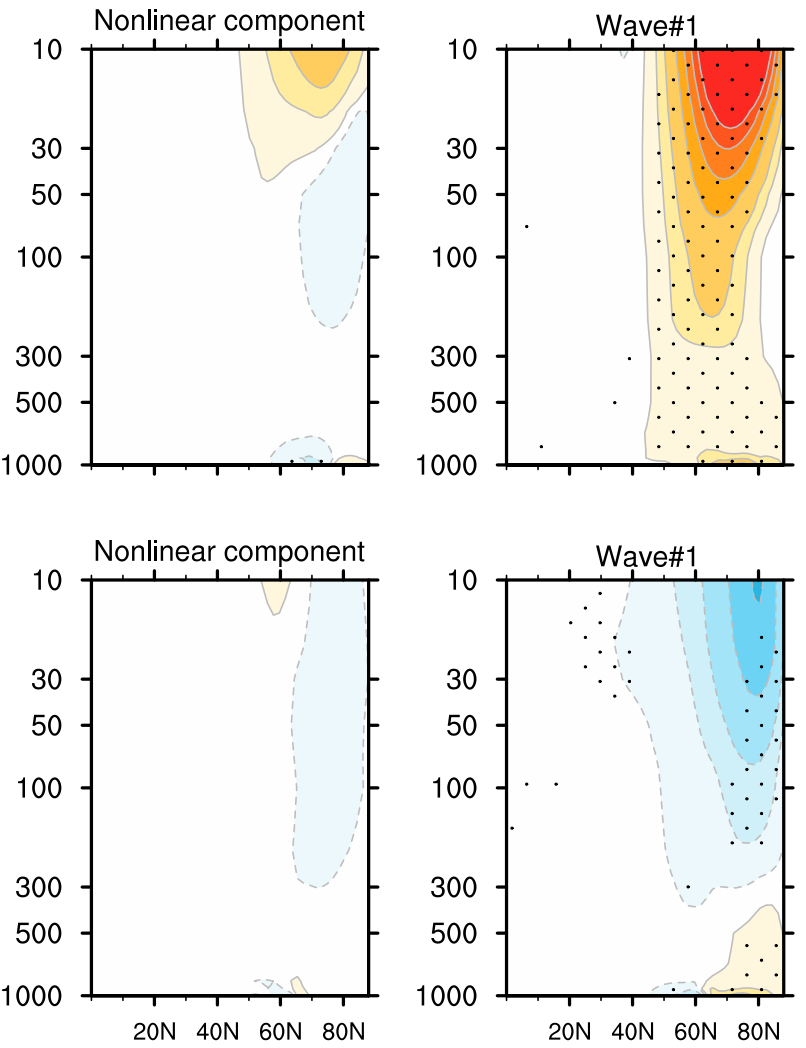

$\mathrm{K} \mathrm{m} / \mathrm{s}$

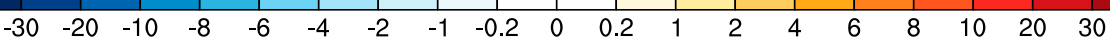

FIG. 6. (a) Zonal-mean eddy heat flux response averaged over December and January in (from left to right) $\Delta \mathrm{ICE} \mathrm{Atlantic}_{\mathrm{A}}$, its linear, nonlinear, and wave-1 components. (b) As in (a), but for $\Delta \mathrm{ICE}_{\text {Pacific }}$. Stippling indicates that the response is statistically significant at the $95 \%$ confidence level.

response to surface heating (Hoskins and Karoly 1981). On the other hand, the response pattern also projects onto the negative phase of the NAM, implying a role for synoptic eddy feedback (Lorenz and Hartmann 2003). Similarly, in $\triangle \mathrm{ICE}_{\text {Pacific }}$, the positive anomaly over the northwestern Pacific (cross hatches) is associated with the linear response to sea ice loss.

Now we consider linear wave interference. The positive anomaly in the Barents-Kara Sea and the negative anomaly in the Pacific and northeastern Asia are largely in phase with the climatological wavenumber 1 in $\Delta \mathrm{ICE}_{\text {Atlantic }}$ (Fig. 7b). Therefore, the forced response due to sea ice loss in the Barents-Kara Sea constructively interferes with the climatological wavenumber 1 , thereby enhancing upward wave propagation. By contrast, the positive anomaly in the northwestern Pacific in $\Delta \mathrm{ICE}_{\text {Pacific }}$ is out of phase with the climatological wave 1 (destructive interference) and suppresses upward wave propagation. At $30 \mathrm{hPa}$ (Fig. 7a), a weakening of the polar vortex (positive anomalies) in $\Delta \mathrm{ICE}_{\mathrm{Atlantic}}$ and strengthening of the polar vortex (negative anomalies) in $\triangle \mathrm{ICE}_{\text {Pacific }}$ are both consistent with tropospheric linear wave interference and changes in upward wave propagation.

\section{e. Comparison of WACCM and CAM4}

As discussed above, we have conducted identical prescribed sea ice loss experiments with CAM4. Given the same sea ice loss, the WACCM and CAM4 show nearly identical changes in Arctic net surface energy flux (Fig. 2). Therefore, any differences in circulation response between WACCM and CAM4, can be attributed to the different model configurations.

Figure 8 shows the seasonal cycle of the zonal-mean zonal wind response in $\Delta \mathrm{ICE}_{\text {total_CAM4 }}$. There are striking differences between the responses in CAM4 compared to WACCM (recall Fig. 3). In general, the tropospheric circulation response (easterly wind anomalies in the band $50^{\circ}-70^{\circ} \mathrm{N}$ ) is considerably weaker in CAM4 than WACCM, especially in DJF 


\section{a) $\mathrm{Z}$ at $30 \mathrm{hPa}$}

Dec-Jan
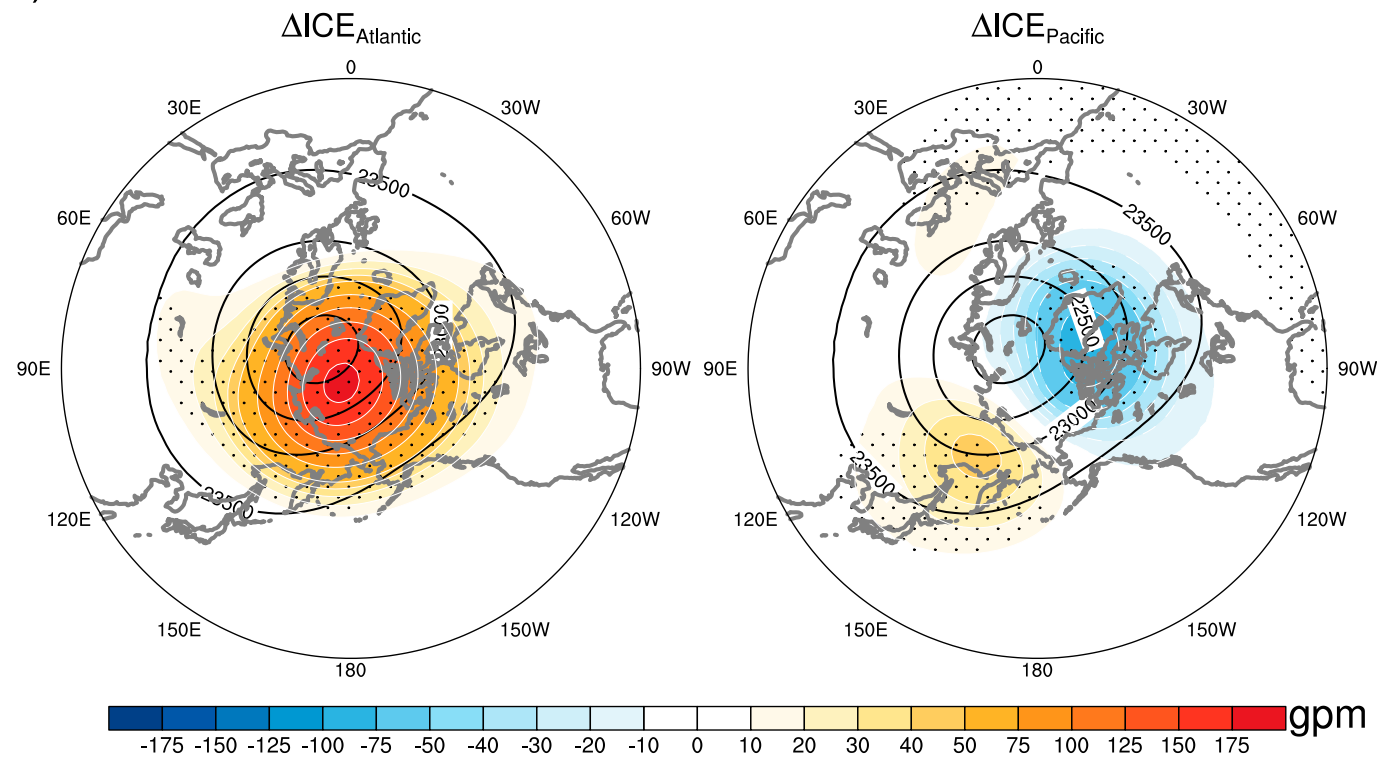

b) $\mathrm{Z}$ at $300 \mathrm{hPa}$

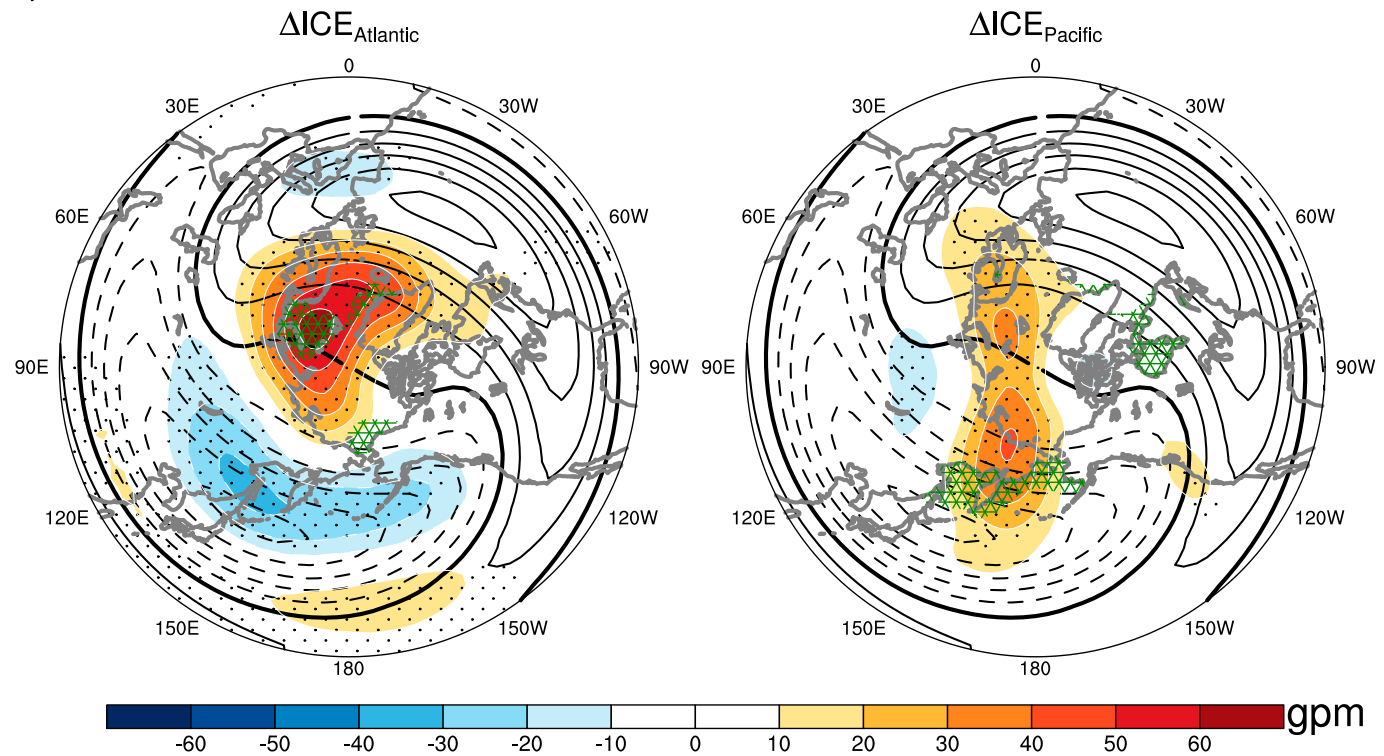

FIG. 7. (a) December-January geopotential height response at $30 \mathrm{hPa}$ in $\Delta \mathrm{ICE}_{\text {Atlantic }}$ and $\Delta \mathrm{ICE} \mathrm{Pacific}_{\text {. }}$ (b) As in (a), but for the response at $300 \mathrm{hPa}$. Climatological geopotential height at $30 \mathrm{hPa}$ (contours; interval of $500 \mathrm{gpm}$ ) is superposed in (a) to show the stratospheric polar vortex. Climatological wave-1 geopotential height (contours; interval of $30 \mathrm{gpm}$ ) is superposed in (b) to show the wave interference between forced response and climatological waves. Green cross hatching in (b) denotes regions where sea ice concentration loss exceeds $15 \%$.

and March-May (MAM), and there is no evidence for enhanced westerlies in the middle latitudes. In the stratosphere, the winter circulation response in CAM4 is characterized by a strengthening of the polar vortex, opposite to that in WACCM. The difference in winter stratospheric responses coincides with a difference in climatology: the mean winter polar vortex in CAM4 is roughly $10 \mathrm{~m} \mathrm{~s}^{-1}$ stronger than in WACCM. The difference in winter climatologies, in turn, can be related to the strong E-P divergence near the model lid (above $10 \mathrm{hPa}$ ) in CAM4, which does not appear in WACCM (not shown), consistent with Sassi et al. (2010). The spring stratospheric response in CAM4 resembles the response in WACCM, with a little larger magnitude in the lower 


\section{$[\mathrm{U}]$ in CAM4 ( $\left.\triangle \mathrm{ICE}_{\text {total_CAM4 }}\right)$}

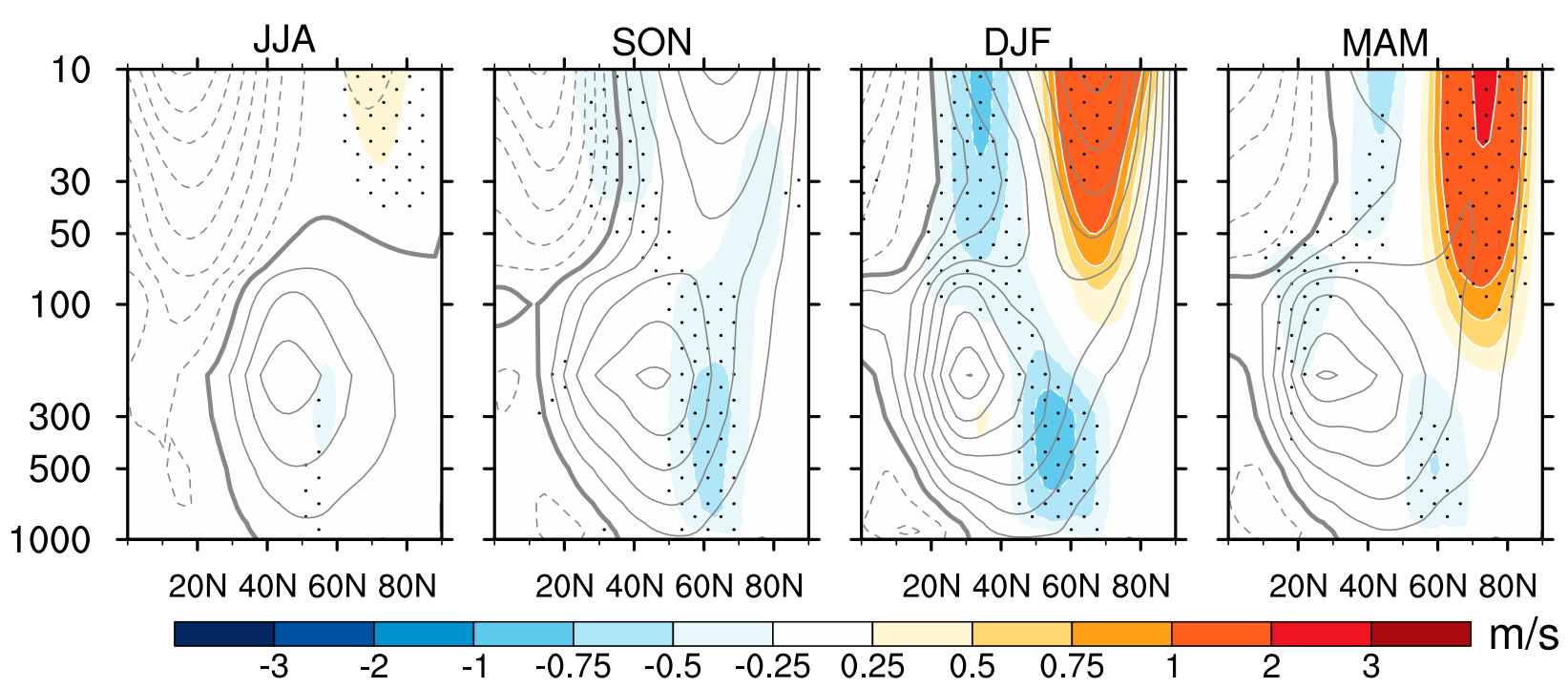

FIG. 8. As in Fig. 3, but for the zonal wind response in $\Delta \mathrm{ICE}_{\text {total_cam4. }}$

stratosphere. In summer and autumn, both models exhibit weak responses in the troposphere and stratosphere.

Figure 9 shows the evolution of the polar cap $\left(65^{\circ}-\right.$ $90^{\circ} \mathrm{N}$ ) geopotential height response from December to April in $\triangle \mathrm{ICE}_{\text {total }}$ and $\triangle \mathrm{ICE}_{\text {total_CAM4 }}$, and their difference. Polar cap geopotential height is commonly used as a simple proxy for the NAM index (e.g., Peings and Magnusdottir 2014): a positive anomaly implies a negative NAM response or a weakening of the polar vortex in the stratosphere, and vice versa. In the troposphere, both models show positive anomalies throughout the winter and spring, indicative of a negative NAM response. In the stratosphere, the response in WACCM is characterized by negative NAM in winter and positive NAM in spring, consistent with the results shown earlier. The stratospheric response in CAM4 is similar to WACCM, but the transition from negative to positive NAM occurs much earlier, in mid-December. The difference between the WACCM and CAM4 responses shows significant positive anomalies (negative NAM) in the stratosphere from December to March, which intermittently extend downward into the troposphere in mid-January, February, and March with over $95 \%$ statistical significance (Fig. 9c). This downward influence pattern is similar to those discussed in Baldwin and Dunkerton (2001), Peings and Magnusdottir (2014), and Kim et al. (2014), and suggests that differences in the stratospheric response due to model configuration subsequently affects the tropospheric response as a consequence of downward propagation.

To help understand the mechanism of the different circulation responses in WACCM and CAM4, we show the January-February averaged E-P flux responses in the two models and their difference (Fig. 10). Overall, there is more horizontal and vertical wave propagation into the polar stratosphere in WACCM compared to CAM4, which induces more wave dissipation (negative anomalies) in the lower stratosphere. In contrast, there is downward wave propagation poleward of $60^{\circ} \mathrm{N}$ in CAM4, which is responsible for the weaker dissipation in the lower stratosphere. The difference in E-P flux responses highlights the greater horizontal and vertical wave propagation into the polar stratosphere in WACCM compared to CAM4 (Fig. 10c). This explains why the winter polar vortex weakens in WACCM but strengthens in CAM4.

In the troposphere, both models exhibit upward wave propagation in the latitude band $40^{\circ}-60^{\circ} \mathrm{N}$, with anomalous E-P convergence in the extratropical upper troposphere. These patterns are in agreement with other modeling studies (e.g., Peings and Magnusdottir 2014). However, the upward wave propagation is stronger in WACCM compared to CAM4, accompanied by larger E-P divergence around $40^{\circ} \mathrm{N}$ and E-P convergence around $60^{\circ} \mathrm{N}$. These larger E-P divergence/convergence anomalies act to extract more momentum from the high latitudes and deposit it in the middle latitudes, causing a larger negative NAM response in WACCM compared to CAM4.

\section{f. Impact of autumn sea ice loss on winter and spring atmospheric circulation}

As discussed in the introduction, some studies have speculated that the winter NAO/NAM response to 


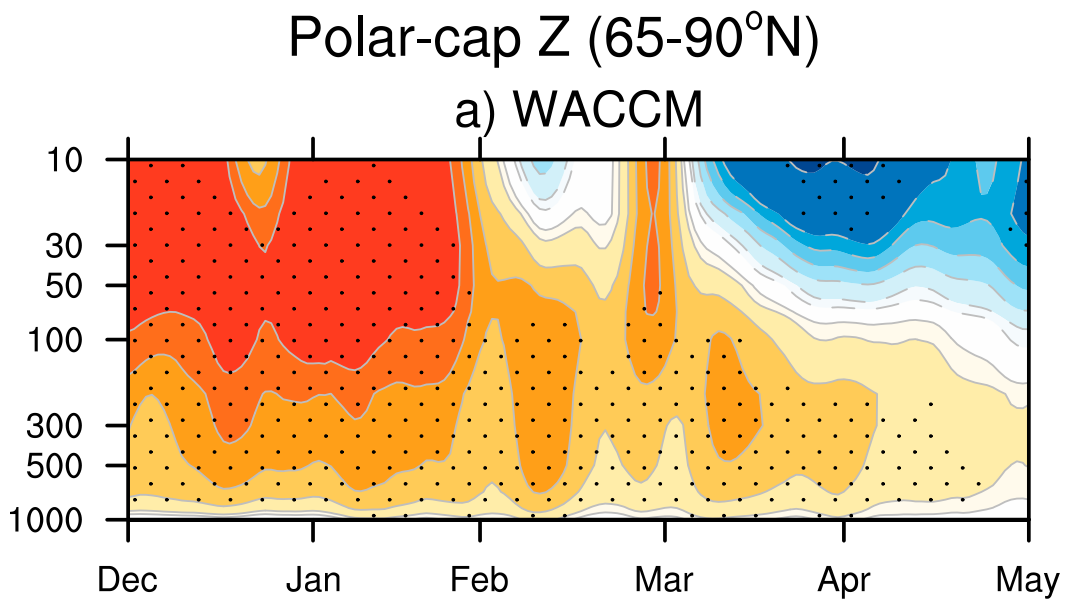

b) CAM4
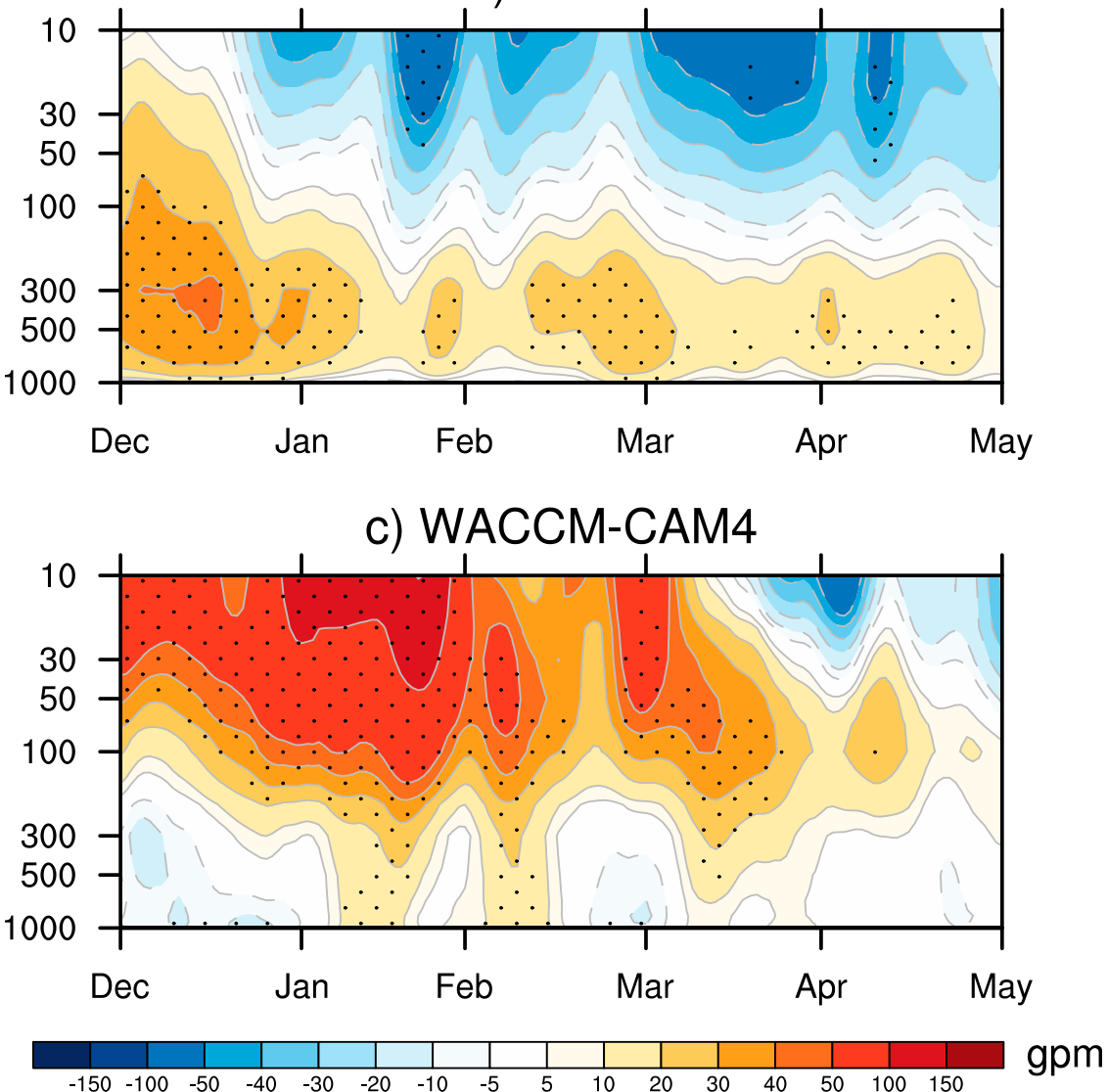

FIG. 9. Evolution of polar cap $\left(65^{\circ}-90^{\circ} \mathrm{N}\right)$ geopotential height response to Arctic sea ice loss

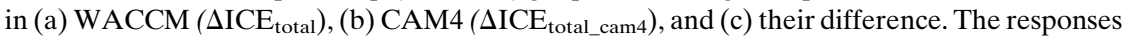
are smoothed by 7 -day running average. The horizontal tick marks denote the first day of each month. Stippling indicates that the response is statistically significant at the $95 \%$ confidence level.

Arctic sea ice loss is a delayed response to the larger ice loss in autumn rather than a simultaneous response to the smaller ice loss in winter (e.g., Francis et al. 2009). Here we test this hypothesis by comparing the circulation responses in $\triangle \mathrm{ICE}_{\text {autumn }}$ and $\Delta \mathrm{ICE}_{\text {total }}$. Recall that the ice loss in $\triangle \mathrm{ICE}_{\text {autumn }}$ is restricted to the months August-November (Table 1). However, there is some residual ice loss through 15 December due to 


\section{E-P response in Jan-Feb}

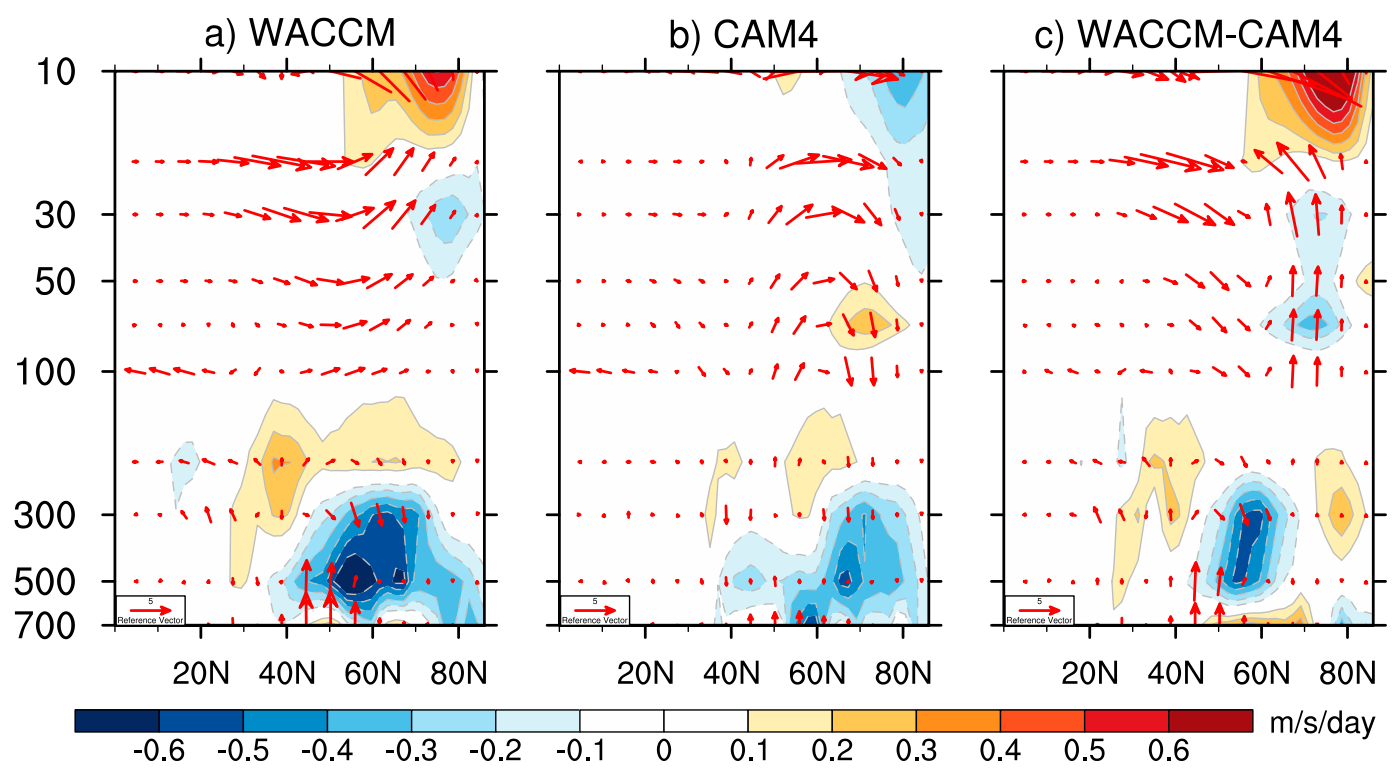

FIG. 10. January-February averaged Eliassen-Palm flux (vectors) and E-P divergence response (shading) to

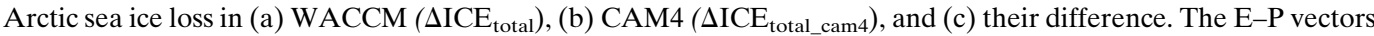
are first divided by the square root of (1000/pressure) (Taguchi and Hartmann 2006), and then multiplied by a scale factor of 3 above $100 \mathrm{hPa}$ to enhance the small vectors in the stratosphere.

interpolation of the prescribed sea ice cover from monthly to daily values within the model. This is reflected in a small nonzero surface energy flux response in December in $\triangle \mathrm{ICE}_{\text {autumn }}$ (Fig. 2). Prior to December, the surface energy flux response in $\triangle \mathrm{ICE}_{\text {autumn }}$ is almost identical to that in $\Delta \mathrm{ICE}_{\text {total }}$. After 15 December, there

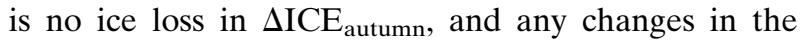
tropospheric or stratospheric circulation must come from ice loss earlier in the season.

Figure 11a shows the evolution of the polar cap geopotential height response in $\triangle \mathrm{ICE}_{\text {autumn }}$ from December to April. Significant positive anomalies occur in the troposphere in December, and in the stratosphere in January. Although there is a weak signature of apparent downward propagation from January to April, the amplitudes are small and not statistically significant except in early April in the lower troposphere. Restricting the polar cap geopotential height response to the Atlantic sector $\left(90^{\circ} \mathrm{W}-\right.$ $40^{\circ} \mathrm{E}$ ) yields a stronger apparent downward influence from the stratosphere to the troposphere (Fig. 11b). In particular, a weakening of the stratospheric polar vortex in January is followed by a statistically significant response near the surface from mid-February through early April. This suggests that autumn sea ice loss is able to affect the late winter and early spring tropospheric circulation in the Atlantic sector through a stratospheric pathway.

The spatial distributions of monthly $1000-\mathrm{hPa}$ geopotential height anomalies in $\triangle \mathrm{ICE}_{\text {autumn }}$ from December to April are shown in Fig. 12. Recall that in early December there is still some residual ice loss, mostly in the Barents-Kara Sea, Hudson Bay, and the Bering Sea. These regions show negative $1000-\mathrm{hPa}$ geopotential height anomalies in December, consistent with the local baroclinic response to ice loss (Deser et al. 2007). These local responses disappear once the ice loss is completely removed, so that the circulation response is weak and mostly insignificant in January. From February to April, there is a statistically significant circulation response in the Atlantic region that resembles the negative phase of the NAO, with positive anomalies (maximum values $\sim 15 \mathrm{gpm}$ ) between Greenland and Scandinavia and negative anomalies to the south. The daily time series of the NAO index, shown in Fig. 12b, highlights the evolution of the NAO response to autumn sea ice loss. The negative NAO response begins in late January and amplifies over the next month, with three pulses of stronger anomalies in late February, mid-March, and late March), consistent with Fig. 11b. Here, the daily NAO index was computed by projecting daily $500-\mathrm{hPa}$ geopotential height anomalies onto the leading EOF of $500-\mathrm{hPa}$ geopotential height anomalies during December-May over the Atlantic sector $\left(20^{\circ}-90^{\circ} \mathrm{N}\right.$, $\left.90^{\circ} \mathrm{W}-40^{\circ} \mathrm{E}\right)$ in $\mathrm{ICE}_{\text {control }}$.

Since the circulation response in $\triangle \mathrm{ICE}_{\text {total }}$ also exhibits a negative NAM/NAO pattern, it is interesting to evaluate how much of the total response is 


\section{Polar-cap Z in $\triangle \mathrm{ICE}_{\text {autumn }}$}
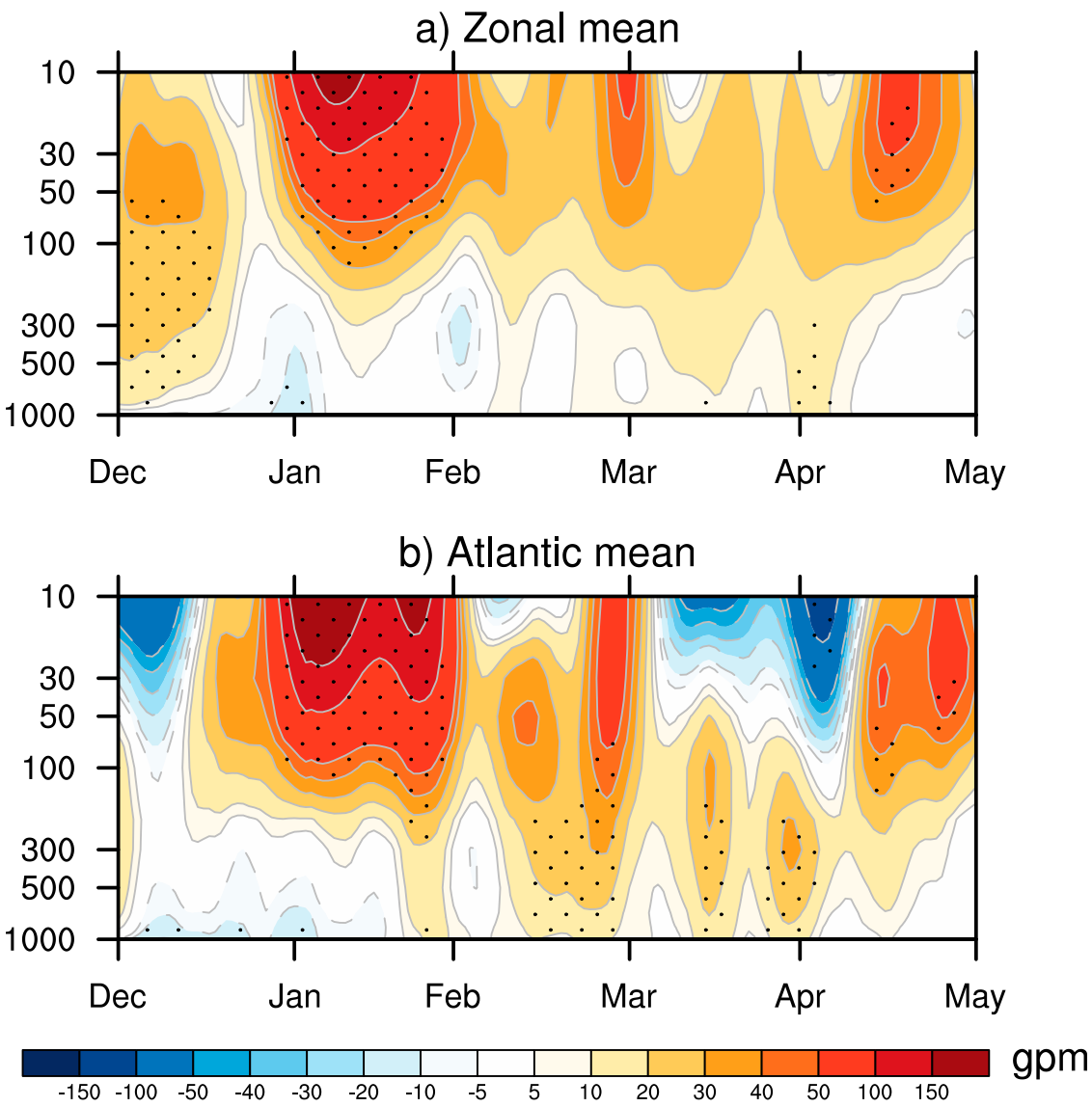

FIG. 11. (a) Evolution of polar cap $\left(65^{\circ}-90^{\circ} \mathrm{N}\right)$ geopotential height response to autumn sea ice loss $\left(\Delta \mathrm{ICE}_{\text {autumn }}\right)$. (b) As in (a), but for the Atlantic sector $\left(90^{\circ} \mathrm{W}-40^{\circ} \mathrm{E}\right)$. The responses are smoothed by 7-day running average. Stippling indicates that the response is statistically significant at the $95 \%$ confidence level. The horizontal tick marks denote the first day of each month.

contributed by autumn sea ice loss. Figure 13 compares the February-April 500- and 1000-hPa geopotential height responses in $\triangle \mathrm{ICE}_{\text {total }}$ and $\triangle \mathrm{ICE}_{\text {autumn }}$. The NAO response in $\triangle \mathrm{ICE}_{\text {autumn }}$ exhibits an equivalent barotropic structure, with amplified anomalies at $500 \mathrm{hPa}$ compared to $1000 \mathrm{hPa}$; the $500-\mathrm{hPa}$ response also includes an additional downstream center of action over eastern Asia that resembles a Rossby wave train. Comparison of the 500-hPa responses in $\triangle \mathrm{ICE}_{\text {total }}$ and $\Delta \mathrm{ICE}_{\text {autumn }}$ shows that much of the February-April circulation response in the Atlantic sector in $\Delta \mathrm{ICE}_{\text {total }}$ comes from autumn sea ice loss (via the stratosphere), whereas the circulation changes in other regions (e.g., Pacific) are due to the contemporaneous sea ice loss.

\section{g. Surface climate response to projected Arctic sea ice loss}

Next we turn our attention to the surface climate response. Figure 14 shows the winter (DJF) and spring
[February-April (FMA)] responses of 2-m air temperature (shading) and sea level pressure (SLP; contours) in $\Delta \mathrm{ICE}_{\text {total }}$ and $\triangle \mathrm{ICE}_{\text {autumn. }}$. We shall first consider the responses in $\triangle \mathrm{ICE}_{\text {total }}$. Both seasons show a similar pattern of SLP response consisting of negative anomalies over the North Pacific and Canada, and positive anomalies over high-latitude Eurasia. The amplitude of this wave-1 response pattern is stronger in DJF than FMA. The terrestrial surface temperature response is influenced by both thermodynamic and dynamical factors. On the one hand, the anomalous heating of the lower troposphere above regions of ice loss warms the adjacent high-latitude continents via horizontal diffusion (advection by the climatological submonthly transients; Deser et al. 2010). This thermodynamic warming is evident in both seasons over land areas in proximity to regions of sea ice loss. On the other hand, seasonal-mean atmospheric circulation anomalies acting on the climatological mean horizontal temperature gradient can dynamically induce temperature changes. This effect is 
$\Delta \mathrm{ICE}_{\text {autumn }}$

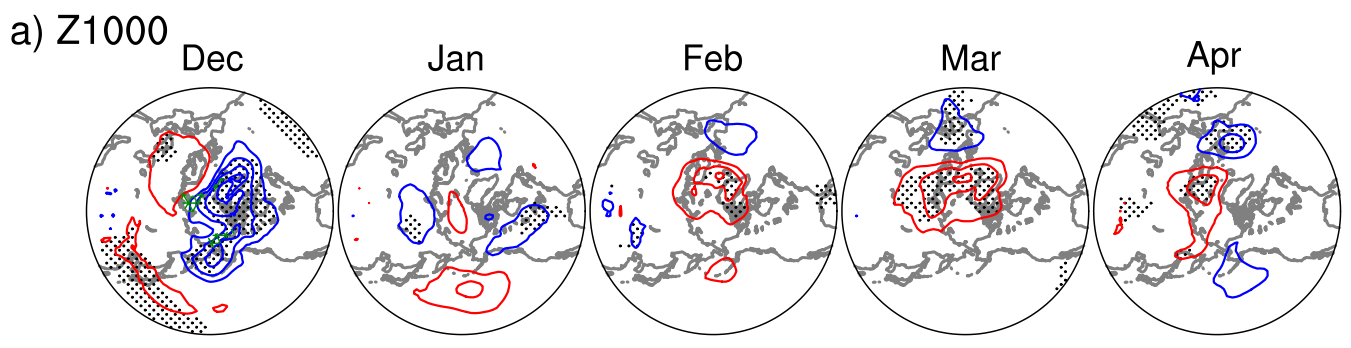

b) daily NAO index

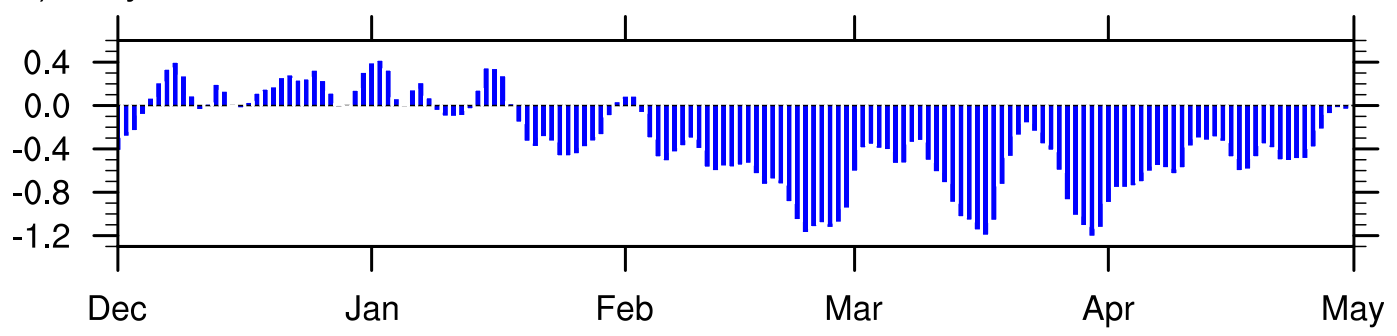

FIG. 12. (a) 1000-hPa geopotential height response in $\triangle \mathrm{ICE}_{\text {autumn }}$ during December-April The contour interval is $5 \mathrm{gpm}$, with positive (negative) values in red (blue) and the zero contours omitted. Small areas of green cross hatching denote regions where sea ice concentration loss in the first half of December exceeds $15 \%$. Stippling indicates that the response is statistically significant at the $95 \%$ confidence level. (b) Response of the daily NAO index in $\Delta \mathrm{ICE}_{\text {autumn }}$. The horizontal tick marks denote the first day of each month.

particularly evident over Eurasia, where the high-latitude positive SLP anomaly (a strengthening of the Siberian high) produces strong cold air advection, leading to cooling (up to $-1.2^{\circ} \mathrm{C}$ ) over central Eurasia in DJF. This dynamically induced cooling is reduced in magnitude in FMA due to the weakening of the high pressure response. It is also worth noting that the lack of high pressure anomalies over North America in either season means that dynamically induced cooling does not occur in this region. The winter surface air temperature and atmospheric circulation responses found here are largely in agreement with previous modeling studies (Mori et al. 2014; Screen et al. 2015).

The FMA air temperature responses in $\triangle \mathrm{ICE}_{\text {autumn }}$ are entirely attributable to dynamical effects, as there is no ice loss by design. In particular, the positive SLP response induces cold air advection over northern Eurasia, explaining the significant cooling in that region (right panel of Fig. 14b). Note that this dynamically induced cooling does not have to compete with thermodynamically induced warming as there is no ice loss during FMA in this experiment. Thus, although the Siberian high anomaly is of similar magnitude in $\triangle \mathrm{ICE}_{\text {total }}$ and $\triangle \mathrm{ICE}_{\text {autumn }}$, the surface temperature responses are distinct, reflecting the additional role of direct thermodynamic warming from the ice loss itself in $\triangle \mathrm{ICE}_{\text {total }} . \Delta \mathrm{ICE}_{\text {autumn }}$ also shows a weak but statistically significant warming in DJF over portions of northeastern Canada and Greenland, due to residual ice loss in the first half of December.

\section{Summary and discussion}

\section{a. Summary}

We used the "high-top" WACCM atmospheric model to investigate the response of the tropospheric and stratospheric circulation to projected late twenty-firstcentury Arctic sea ice loss. Our results are based on large sample sizes (160 for each experiment), ensuring robust statistics. Our key findings are summarized as follows.

The tropospheric circulation response to the imposed Arctic sea ice loss resembles the negative phase of the NAM, with the largest amplitude in winter, while the less well-known stratospheric response transitions from a slight weakening of the polar vortex in winter to a robust strengthening of the vortex in spring. The lack of a significant winter stratospheric circulation response is shown to be a consequence of largely cancelling effects from sea ice loss in the Atlantic and Pacific sectors, which drive opposite-signed changes in upward wave propagation from the troposphere to the stratosphere. Further analyses reveal that linear wave interference appears to explain the sensitivity of the stratospheric circulation response to the different geographical locations of sea ice loss.

Identical experiments conducted with CAM4, WACCM's low-top counterpart, provide evidence for the importance of the representation of the stratosphere in the stratospheric and tropospheric circulation response to Arctic 
a) $\mathrm{Z}$ at $500 \mathrm{hPa}$

\section{Feb-Mar-Apr}

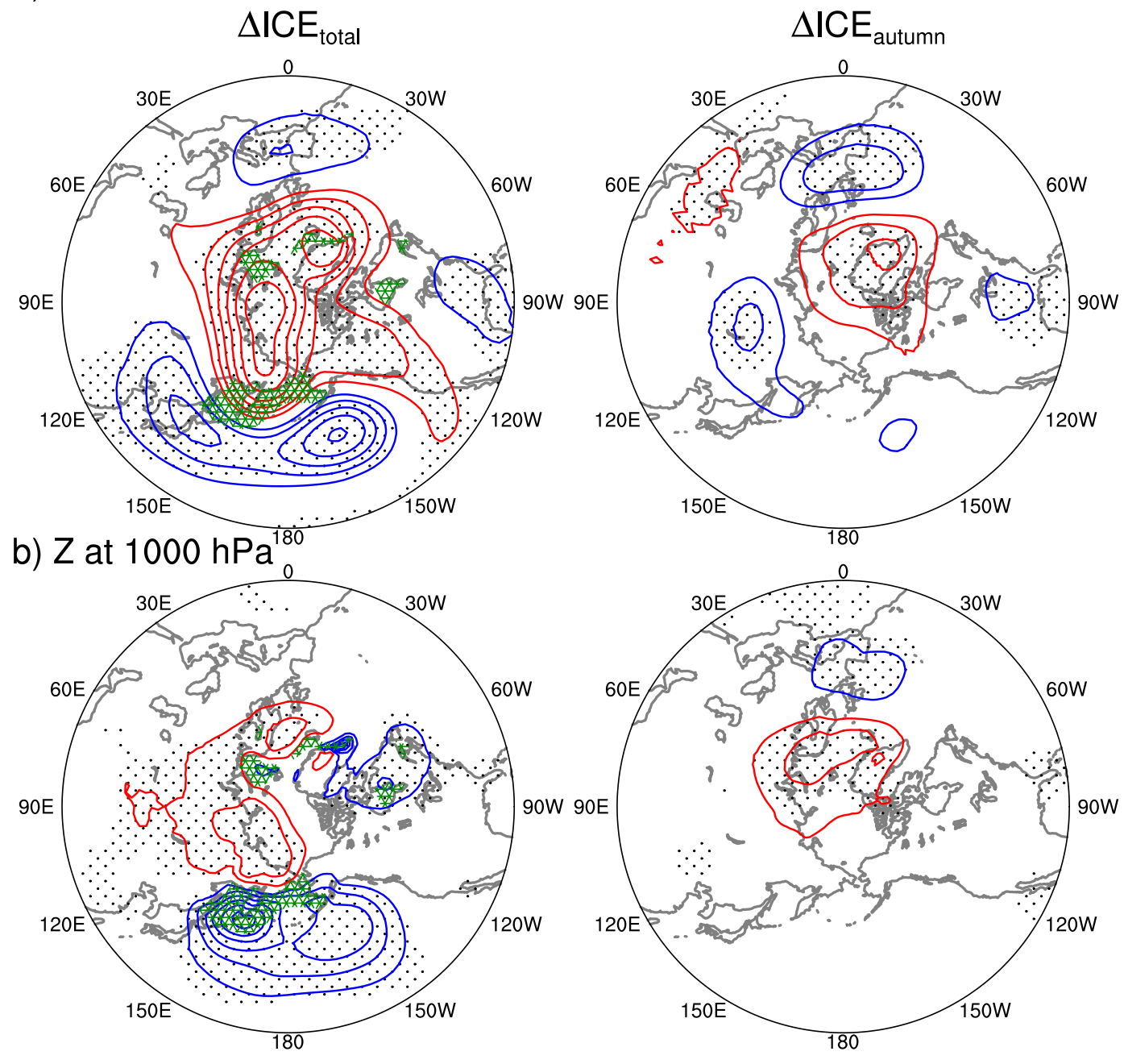

FIG. 13. Geopotential height response averaged over February, March, and April in $\Delta \mathrm{ICE}_{\text {total }}$ and $\Delta \mathrm{ICE}_{\text {autumn }}$ at (a) 500 and (b) $1000 \mathrm{hPa}$. The contour interval is $5 \mathrm{gpm}$, with positive (negative) values in red (blue) and the zero contours omitted. Green cross hatching denotes the regions where sea ice concentration loss exceeds $15 \%$. Stippling indicates that the response is statistically significant at the $95 \%$ confidence level.

sea ice loss. In particular, the results are suggestive of a downward influence of the stratospheric response on the troposphere, but differences in model physics in addition to stratospheric representation preclude a more definitive conclusion. Finally, we showed that autumn sea ice loss causes a weakening of the stratospheric polar vortex in January, followed by a small but significant tropospheric response in late winter and early spring that resembles the negative phase of the NAO. Thus, the stratosphere plays the role of an atmospheric "bridge" between autumn sea ice loss and late winter/early spring NAO. The midwinter (DJF) atmospheric circulation response, however, is dominated by the effects of winter ice loss. Further, autumn ice loss, via the stratospheric bridge mechanism, only explains the late winter/early spring tropospheric circulation response over the Atlantic sector; the Pacific sector response is due to contemporaneous sea ice loss.

Finally, we have shown that the impact of Arctic sea ice loss on winter and spring surface temperatures over the high-latitude continents is a balance between thermodynamically induced warming as air from the warmer Arctic Ocean mixes southward, and dynamically induced cooling associated with an enhanced Siberian high.

\section{b. Discussion}

The results presented above highlight a number of issues. An important one is the sensitivity of the 
a) Dec-Jan-Feb

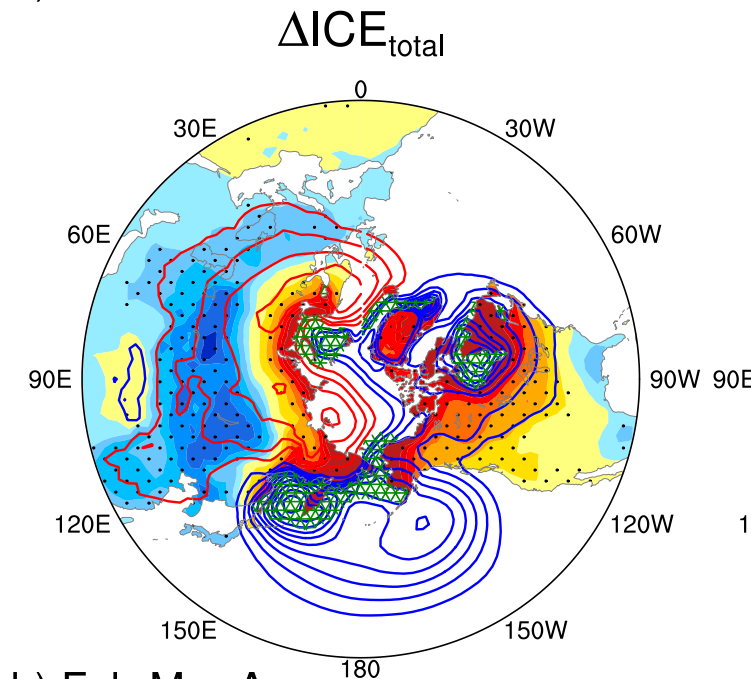

\section{TREFHT \& SLP}

b)

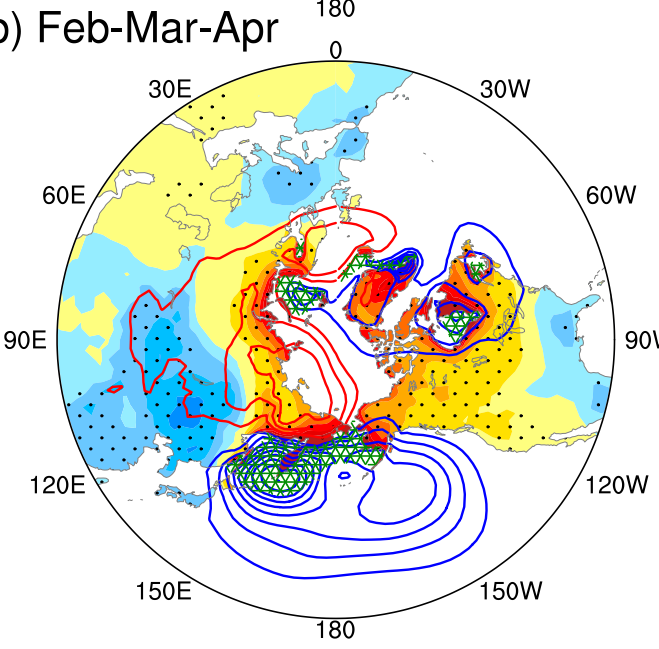

$\Delta \mathrm{ICE}_{\text {autumn }}$

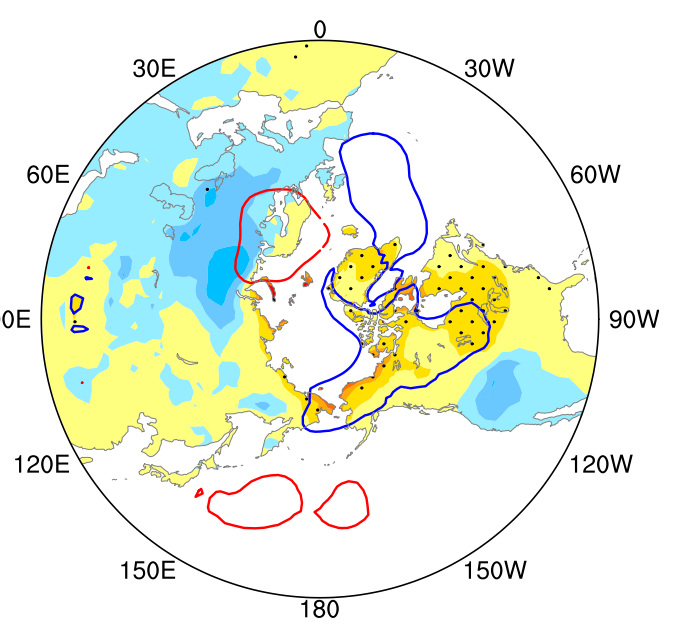

90W

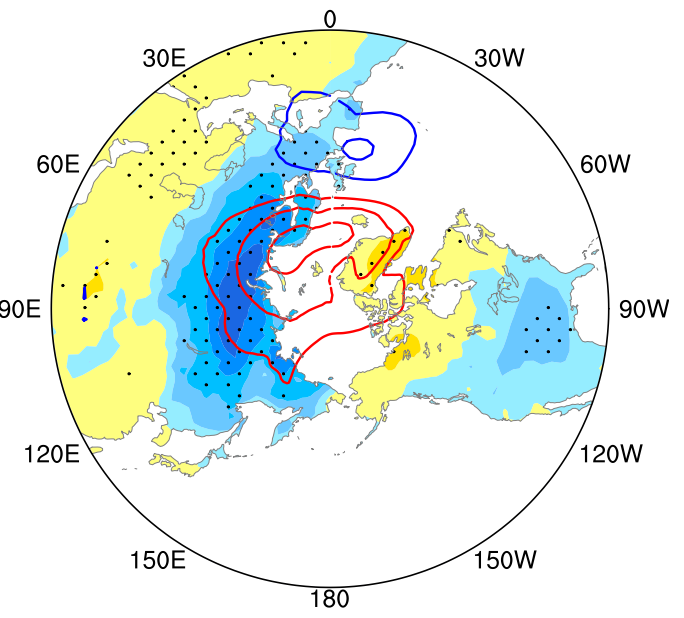
$90 \mathrm{~W}$

FIG. 14. The 2-m air temperature (shading; ${ }^{\circ} \mathrm{C}$ ) and sea level pressure (contours) responses in $\Delta \mathrm{ICE}_{\text {total }}$ and $\Delta \mathrm{ICE}_{\text {autumn }}$ in (a) winter (DJF) and (b) spring (FMA). The contour interval is $0.5 \mathrm{hPa}$, with positive (negative) values in red (blue) and the zero contours omitted. Green cross hatching denotes the regions where sea ice concentration loss exceeds $15 \%$. Stippling indicates that the $2-\mathrm{m}$ air temperature response is statistically significant at the $95 \%$ confidence level.

stratospheric circulation response to the geographical location of the sea ice loss, which we have shown is due to whether the ice loss leads to constructive or destructive interference between the forced and climatological tropospheric zonal wave 1. Specifically, our $\Delta \mathrm{ICE}_{\text {Atlantic }}$ and $\Delta \mathrm{ICE}_{\text {Pacific }}$ experiments have implications for understanding why recent modeling studies on the stratospheric circulation response to Arctic sea ice loss show inconsistent results. Other than model dependence, we argue that differences in sea ice forcing location in these modeling studies can have a large influence on the stratospheric circulation response. Particularly, the sea ice loss used in Kim et al. (2014) is mostly in the Barents and Kara Seas, thus the stratospheric circulation response is similar to our $\Delta \mathrm{ICE}_{\text {Atlantic. This is also in agreement with the empirical }}$ study by Feldstein and Lee (2014). On the other hand, when the full geographic distribution of sea ice loss is considered, the stratospheric response becomes more variable, in some cases dominated by effects from the Barents-Kara Sea ice loss [e.g., the present-day ice loss experiment in Peings and Magnusdottir (2014)], and in 
others by the effects from the Pacific ice loss (Cai et al. 2012), or without a statistically significant structure [e.g., the future sea ice loss experiment in Peings and Magnusdottir (2014); Screen et al. (2013); Sun et al. (2014)]. The extent to which the different stratospheric circulation responses affect the tropospheric response remains an open question.

A second issue relates to whether the atmospheric circulation response to Arctic sea ice loss depends on the representation of the stratosphere. Indeed, we found that WACCM and CAM4 have opposite winter stratospheric circulation responses to the same sea ice forcing. Intriguingly, the difference between the stratospheric circulation responses in the two models intermittently extends downward into the troposphere. This apparent downward influence is suggestive that the lack of a wellresolved stratosphere in CAM4 may contribute to its weaker lower-tropospheric NAM response compared to WACCM; however, we cannot rule out the possibility that other structural differences between the two models may also play a role.

One question we have not addressed is why the winter stratospheric wave propagation and circulation responses in WACCM and CAM4 are distinct. Note that our Eliassen-Palm flux analysis can only provide some diagnostic insight into the possible mechanisms for the circulation response. Without conducting additional transient experiments (e.g., Garfinkel et al. 2012; Watson and Gray 2014), it is impossible to isolate the chain of events connecting the surface to the stratosphere, and to assess how the stratospheric polar vortex is initially modulated. Nevertheless, our analysis does suggest that two factors might contribute to the differences between the two models. One possibility is the difference in the stratospheric basic state. Previous studies have indicated that the polar vortex is normally too strong in the "low-top" model due to more wave reflection near the model lid (e.g., Boville 1984; Boville and Cheng 1988; Sassi et al. 2010; Shaw and Perlwitz 2010). When the stratospheric polar vortex is too strong, it tends to refract more planetary waves into midlatitudes, causing less wave dissipation in high latitudes and a strengthening of the polar vortex. This mechanism was first revealed in Sigmond and Scinocca (2010) for the atmospheric circulation response to a doubling of $\mathrm{CO}_{2}$ and seems likely to be at work here, consistent with our Eliassen-Palm flux analysis (Fig. 10).

The other possibility for the difference lies in the troposphere; in particular, the tropospheric wave interference could be different between the two models. It has been shown that different stratospheric basic states may alter the tropospheric planetary wave structure, particularly in the Arctic (Boville 1984; Shaw and
Perlwitz 2010). Besides, Shaw et al. (2014) found that the Community Climate System Model, version 4 (CCSM4; CAM4's fully coupled counterpart) exhibits a large bias in its tropospheric stationary wave-1 pattern in the Arctic, consistent with the interaction between the planetary wave and the model lid. Figure S2 (in the supplemental material) shows the December-January climatological wave-1 geopotential height at $300 \mathrm{hPa}$ in WACCM and CAM4. Their differences are in good agreement with those in the "high-top" and "low-top" versions of the Canadian model [Fig. 5 "High_C" vs "Low_N" in Shaw and Perlwitz (2010)]. As a consequence, the altered tropospheric waves might be able to trigger different wave interference patterns with the forced response, thus causing different responses in upward wave propagation. In our case, we do observe more wave refraction into midlatitudes and also less upward wave propagation into the stratosphere over the Arctic in CAM4 compared to WACCM (Fig. 10c). Therefore, both mechanisms could potentially contribute to the different stratospheric responses to Arctic sea ice loss in WACCM and CAM4.

Some studies have found that deficiencies in the simulation of stratospheric sudden warmings (SSWs) in low-top models could explain the sensitivity of the tropospheric circulation response to North Atlantic SST anomalies to the representation of the stratosphere (Omrani et al. 2014). Here we examine whether the number of SSWs can also explain the different responses to Arctic sea ice loss in WACCM and CAM4. Table 2 shows the total number of SSWs in the two models, where SSWs are defined as a reversal of the zonal wind at $10 \mathrm{hPa}$ and $60^{\circ} \mathrm{N}$ following Butler et al. (2014). While SSWs occur much more frequently in WACCM than in CAM4, likely due to the turbulent mountain stress parameterization (Richter et al. 2010), the changes in SSW frequency in response to total Arctic sea ice loss are not significant in either model. Therefore, changes in SSW frequency do not appear to explain the different responses to Arctic sea ice loss in the two models.

A third issue concerns the role of the stratospheric bridge in communicating the effects of autumn sea ice loss to the winter/spring tropospheric circulation. The results of our autumn sea ice experiment are consistent with the empirical findings of Jaiser et al. (2013), who showed that Arctic sea ice loss in autumn is associated with enhanced upward wave propagation into the stratosphere and a weakening of the polar vortex in winter. The weakened winter polar vortex in $\triangle \mathrm{ICE}_{\text {autumn }}$ is accompanied by nearly a doubling of SSWs compared to the control run (41 vs 23 ; Table 2). Consistent with the greater frequency of SSWs, the tropospheric circulation response in February and March exhibits a negative 
TABLE 2. Numbers of stratospheric sudden warming in December and January for the WACCM and CAM4 simulations.

\begin{tabular}{ccccccc}
\hline \hline & \multicolumn{9}{c}{ WACCM } & & \multicolumn{2}{c}{ CAM4 } \\
\hline $\mathrm{ICE}_{\text {control }}$ & $\mathrm{ICE}_{\text {total }}$ & $\mathrm{ICE}_{\text {Atlantic }}$ & $\mathrm{ICE}_{\text {Pacific }}$ & $\mathrm{ICE}_{\text {Autumn }}$ & $\mathrm{ICE}_{\text {control }}$ & $\mathrm{ICE}_{\text {total }}$ \\
\hline 23 & 22 & 37 & 14 & 41 & 5 & 7 \\
\hline
\end{tabular}

NAO pattern (Fig. 13). Interestingly, although the equatorward shift of the midlatitude jet in response to the full Arctic sea ice loss occurs in both the Pacific and Atlantic, only the Atlantic sector response is related to autumn sea ice loss via the stratospheric pathway (Fig. 15). In addition, it has been suggested that snow cover changes in October can influence the winter tropospheric circulation via a stratospheric pathway (e.g., Cohen et al. 2007). However, we find only minor changes in October snow in response to autumn sea ice loss (not shown), suggesting that it is the direct influence of the sea ice rather than snow cover anomalies that alters the midwinter stratospheric circulation, which in turn leads to a negative tropospheric NAO response in late winter and early spring.

Finally, our modeling experiments point to competing effects of Arctic sea ice loss on air temperatures over the adjacent continents. On the one hand, Arctic sea ice loss warms the high-latitude continents via thermodynamic processes [enhanced upward turbulent heat fluxes over the Arctic Ocean and subsequent mixing of the warmed air southward by the climatological submonthly transient eddies; Deser et al. (2010)]. On the other hand, changes in the monthly mean circulation can induce dynamical temperature changes via anomalous advection acting on the climatological mean temperature gradient (e.g., Deser et al. 2010; Mori et al. 2014). In agreement with recent studies (e.g., Peings and Magnusdottir 2014; Mori et al. 2014; Screen et al. 2015), we find that circulation-induced cooling associated with an enhanced Siberian high dominates at middle latitudes over Eurasia in both winter and spring, while thermodynamic warming wins out at high latitudes over both continents. In addition, the negative SLP response over Canada in both winter and spring augments the thermodynamic warming over North America. Thus, caution is needed when attributing the effects of Arctic sea ice loss on continental climate, as they represent a balance between competing mechanisms.

In addition to mean temperature changes, some studies have proposed that Arctic sea ice loss will increase the variability of temperature in the extratropics (Francis and Vavrus 2012; Liu et al. 2012). In our experiments $\left(\Delta \mathrm{ICE}_{\text {total }}\right)$, we find that daily temperature variance

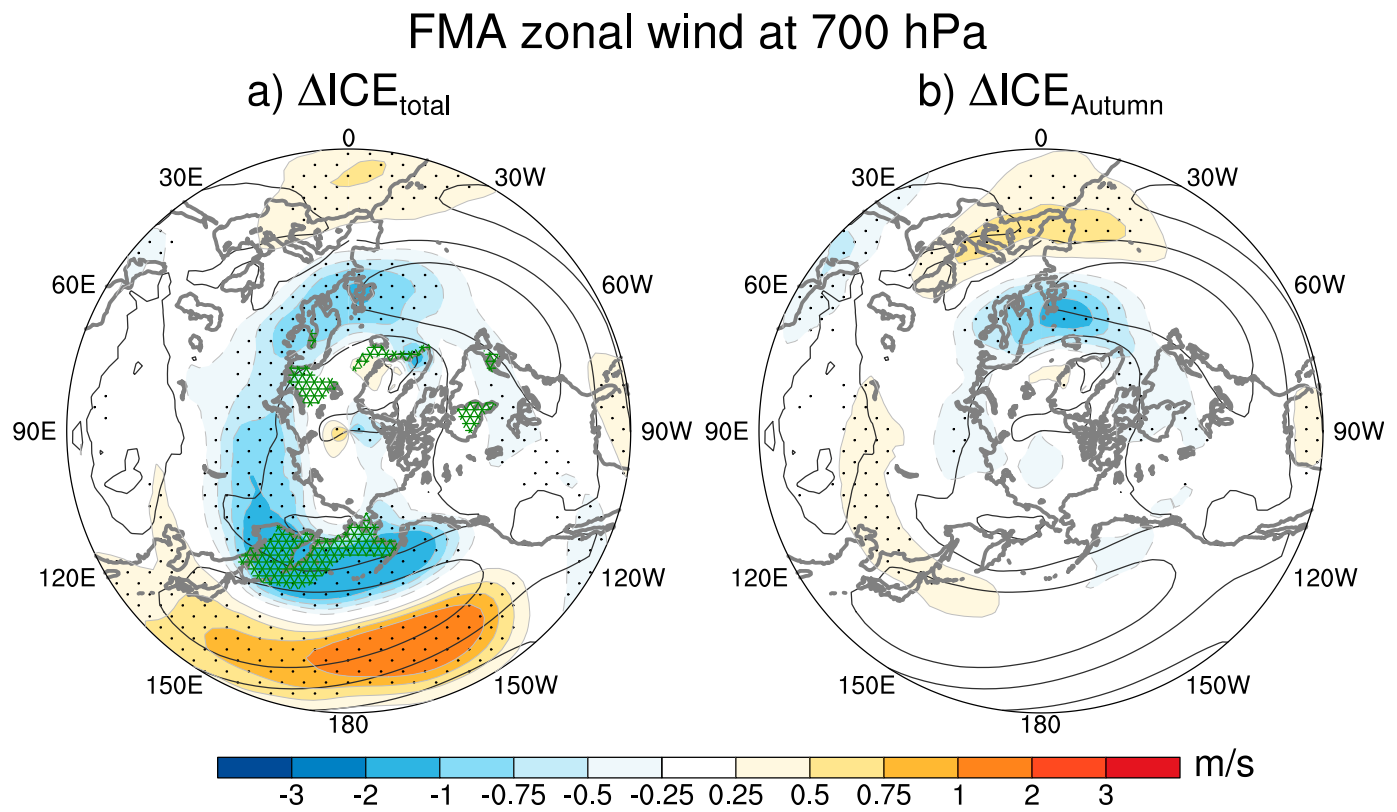

FIG. 15. February-March-April $700-\mathrm{hPa}$ zonal wind response $\left(\mathrm{m} \mathrm{s}^{-1}\right.$; color shading) in (a) $\Delta \mathrm{ICE}_{\text {total }}$ and (b) $\triangle \mathrm{ICE}_{\text {autumn }}$, superimposed upon the climatological mean zonal wind (contour interval of $5 \mathrm{~m} \mathrm{~s}^{-1}$ ). Stippling indicates that the response is statistically significance at the $95 \%$ confidence level based on a two-sided Student's $t$ test. The green cross hatches in (a) denote the regions where sea ice concentration loss exceeds $15 \%$. 


\section{T standard deviation response}

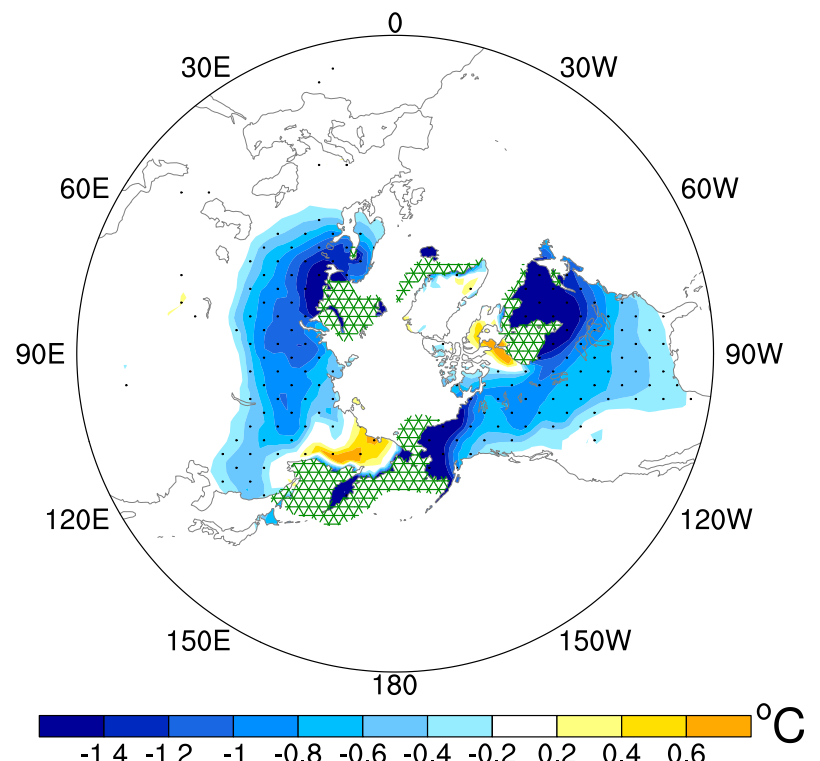

FIG. 16. Response of the standard deviation $\left({ }^{\circ} \mathrm{C}\right)$ of daily temperature at $1000 \mathrm{hPa}$ in winter (DJF) to Arctic sea ice loss in $\Delta \mathrm{ICE}_{\text {total }}$. The monthly mean temperature has been subtracted from the daily temperature values for each year to isolate the submonthly variability. Stippling indicates that the response is statistically significance at the $95 \%$ confidence level based on a two-sided Student's $t$ test. The green cross hatches denote the regions where sea ice concentration loss exceeds $15 \%$.

within a winter season decreases significantly over northern North America and Eurasia, opposite to that conjectured in those studies (Fig. 16). Our results are consistent with observational findings of Screen (2014) who found that Arctic amplification decreases temperature variance in northern middle and high latitudes. They are also in agreement with modeling results shown in Screen et al. (2015, their Fig. 6) based on CAM4 and the Hadley Global Environment Model, version 2 (HadGEM2), as well as the idealized modeling study of Schneider et al. (2015).

Our experiments do not consider the potential role of air-sea coupling in the climate response to Arctic sea ice loss. A recent study conducted with CAM4 shows that without ocean feedbacks, the atmospheric circulation response is confined to the Northern Hemisphere extratropics; whereas, with ocean feedbacks, the response expands to cover the whole globe, resembling a mini global warming pattern that includes an equatorward shift of the intertropical convergence zone (Deser et al. 2015). The extent to which the presence of a wellresolved stratosphere modifies this coupled oceanatmosphere response to Arctic sea ice loss remains to be addressed.

Last, it is worth emphasizing that the effects of future Arctic sea ice loss isolated in this study occur in conjunction with other impacts from elevated greenhouse gas (GHG) concentrations. The relative role of Arctic sea ice loss in the full response to RCP8.5 radiative forcing has been discussed in many studies, including Deser et al. (2010), Mori et al. (2014), and Deser et al. (2015). In agreement with the latter study, we find that Arctic sea ice loss shifts the midlatitude tropospheric westerly jet in WACCM equatorward, offsetting the poleward shift due to enhanced warming of the tropical upper troposphere associated with higher GHGs (not shown). These competing influences result in no net change of the zonal-mean wintertime midlatitude eddy-driven jet in response to RCP8.5 radiative forcing in WACCM (not shown).

Acknowledgments. We wish to thank three anonymous reviewers and Editor John Walsh for the constructive comments and suggestions, and we appreciated valuable discussions with Dr. Lorenzo Polvani during the early stages of this work. This project was supported by a grant from the Office of Polar Programs at the National Science Foundation. We would like to acknowledge high-performance computing support from Yellowstone (ark:/85065/d7wd3xhc) provided by NCAR's Computational and Information Systems Laboratory, sponsored by the National Science Foundation.

\section{REFERENCES}

Baldwin, M. P., and T. J. Dunkerton, 2001: Stratospheric harbingers of anomalous weather regimes. Science, 294, 581-584, doi:10.1126/science. 1063315.

Barnes, E. A., 2013: Revisiting the evidence linking Arctic amplification to extreme weather in midlatitudes. Geophys. Res. Lett., 40, 4728-4733, doi:10.1002/grl.50880.

—, E. Dunn-Sigouin, G. Masato, and T. Woollings, 2014: Exploring recent trends in Northern Hemisphere blocking. Geophys. Res. Lett., 41, 638-644, doi:10.1002/2013GL058745.

Boville, B. A., 1984: The influence of the polar night jet on the tropospheric circulation in a GCM. J. Atmos. Sci., 41, 1132-1142, doi:10.1175/1520-0469(1984)041<1132:TIOTPN>2.0.CO;2.

— circulation model. J. Atmos. Sci., 45, 2591-2606, doi:10.1175/ 1520-0469(1988)045<2591:UBEIAG > 2.0.CO;2.

Butler, A. H., D. W. J. Thompson, and R. Heikes, 2010: The steadystate atmospheric circulation response to climate change-like thermal forcings in a simple general circulation model. J. Climate, 23, 3474-3496, doi:10.1175/2010JCLI3228.1.

- L. L. Polvani, and C. Deser, 2014: Separating the stratospheric and tropospheric pathways of El Niño-Southern Oscillation teleconnections. Environ. Res. Lett., 9, 024014, doi:10.1088/1748-9326/9/2/024014.

Cai, D., M. Dameris, H. Garny, and T. Runde, 2012: Implications of all season Arctic sea- ice anomalies on the stratosphere. Atmos. Chem. Phys., 12,11 819-11 831, doi:10.5194/ acp-12-11819-2012. 
Charlton-Perez, A. J., and Coauthors, 2013: On the lack of stratospheric dynamical variability in low-top versions of the CMIP5 models. J. Geophys. Res. Atmos., 118, 2494-2505, doi:10.1002/jgrd.50125.

Charney, J. G., and P. G. Drazin, 1961: Propagation of planetary disturbances from the lower into the upper atmosphere. J. Geophys. Res., 66, 83-109, doi:10.1029/JZ066i001p00083.

Cohen, J., M. Barlow, P. J. Kushner, and K. Saito, 2007: Stratosphere-troposphere coupling and links with Eurasian land surface variability. J. Climate, 20, 5335-5343, doi:10.1175/ 2007JCLI1725.1.

Deser, C., R. A. Tomas, and S. Peng, 2007: The transient atmospheric circulation response to North Atlantic SST and sea ice anomalies. J. Climate, 20, 4751-4767, doi:10.1175/ JCLI4278.1.

,,-- M. A. Alexander, and D. Lawrence, 2010: The seasonal atmospheric response to projected Arctic sea ice loss in the late twenty-first century. J. Climate, 23, 333-351, doi:10.1175/ 2009JCLI3053.1.

, - - and L. Sun, 2015: The role of ocean-atmosphere coupling in the zonal-mean atmospheric response to Arctic sea ice loss. J. Climate, 28, 2168-2186, doi:10.1175/ JCLI-D-14-00325.1.

Eliassen, A., and E. Palm, 1961: On the transfer of energy by mountain waves. Geofys. Publ., 22, 94-101.

Feldstein, S. B., and S. Lee, 2014: Intraseasonal and interdecadal jet shifts in the Northern Hemisphere: The role of warm pool tropical convection and sea ice. J. Climate, 27, 6497-6518, doi:10.1175/JCLI-D-14-00057.1.

Fletcher, C. G., and P. J. Kushner, 2011: The role of linear interference in the annular mode response to tropical SST forcing. J. Climate, 24, 778-794, doi:10.1175/2010JCLI3735.1.

Francis, J. A., and S. J. Vavrus, 2012: Evidence linking Arctic amplification to extreme weather in mid-latitudes. Geophys. Res. Lett., 39, L06801, doi:10.1029/2012GL051000.

— - W. Chan, D. J. Leathers, J. R. Miller, and D. E. Veron, 2009: Winter Northern Hemisphere weather patterns remember summer Arctic sea-ice extent. Geophys. Res. Lett., 36, L07503, doi:10.1029/2009GL037274.

Garfinkel, C. I., D. L. Hartmann, and F. Sassi, 2010: Tropospheric precursors of anomalous Northern Hemisphere stratospheric polar vortices. J. Climate, 23, 3282-3299, doi:10.1175/ 2010JCLI3010.1.

— T. A. Shaw, D. L. Hartmann, and D. W. Waugh, 2012: Does the Holton-Tan mechanism explain how the quasi-biennial oscillation modulates the Arctic polar vortex? J. Atmos. Sci., 69, 1713-1733, doi:10.1175/JAS-D-11-0209.1.

Hassanzadeh, P., Z. Kuang, and B. F. Farrell, 2014: Responses of midlatitude blocks and wave amplitude to changes in the meridional temperature gradient in an idealized dry GCM. Geophys. Res. Lett., 41, 5223-5232, doi:10.1002/ 2014GL060764.

Honda, M., J. Inoue, and S. Yamane, 2009: Influence of low Arctic sea ice minima on anomalously cold Eurasian winters. Geophys. Res. Lett., 36, L08707, doi:10.1029/2008GL037079.

Hoskins, B. J., and D. J. Karoly, 1981: The steady linear response of a spherical atmosphere to thermal and orographic forcing. J. Atmos. Sci., 38, 1179-1196, doi:10.1175/ 1520-0469(1981)038<1179:TSLROA > 2.0.CO;2.

Jaiser, R., K. Dethloff, and D. Handorf, 2013:Stratospheric response to Arctic sea ice retreat and associated planetary wave propagation changes. Tellus, 65A, 19375, doi:10.3402/ tellusa.v65i0.19375.
Kim, B.-M., S.-W. Son, S.-K. Min, J.-H. Jeong, S.-J. Kim, X. Zhang, T. Shim, and J.-H. Yoon, 2014: Weakening of the stratospheric polar vortex by Arctic sea-ice loss. Nature Commun., 5, 4646, doi:10.1038/ncomms5646.

Liu, J., J. A. Curry, H. Wang, M. Song, and R. M. Horton, 2012: Impact of declining Arctic sea ice on winter snowfall. Proc. Natl. Acad. Sci. USA, 109, 4074-4079, doi:10.1073/ pnas.1114910109.

Lorenz, D. J., and D. L. Hartmann, 2003: Eddy-zonal flow feedback in the Northern Hemisphere winter. J. Climate, 16, 1212 1227, doi:10.1175/1520-0442(2003)16<1212:EFFITN > 2.0.CO;2.

Marsh, D. R., M. J. Mills, D. E. Kinnison, J.-F. Lamarque, N. Calvo, and L. M. Polvani, 2013: Climate change from 1850 to 2005 simulated in CESM1(WACCM). J. Climate, 26, 7372 7391, doi:10.1175/JCLI-D-12-00558.1.

Mori, M., M. Watanabe, H. Shiogama, J. Inoue, and M. Kimoto, 2014: Robust arctic sea-ice influence on the frequent Eurasian cold winters in past decades. Nat. Geosci., 7, 869-873, doi:10.1038/ngeo2277.

Nakamura, T., K. Yamazaki, K. Iwamoto, M. Honda, Y. Miyoshi, Y. Ogawa, and J. Ukita, 2015: A negative phase shift of the winter $\mathrm{AO} / \mathrm{NAO}$ due to the recent Arctic sea-ice reduction in late autumn. J. Geophys. Res. Atmos., 120, 3209-3227, doi:10.1002/2014JD022848.

Neale, R. B., J. Richter, S. Park, P. H. Lauritzen, S. J. Vavrus, P. J. Rasch, and M. Zhang, 2013: The mean climate of the Community Atmosphere Model (CAM4) in forced SST and fully coupled experiments. J. Climate, 26, 5150-5168, doi:10.1175/ JCLI-D-12-00236.1.

Nishii, K., H. Nakamura, and T. Miyasaka, 2009: Modulations in the planetary wave field induced by upward-propagating Rossby wave packets prior to stratospheric sudden warming events: A case-study. Quart. J. Roy. Meteor. Soc., 135, 39-52, doi:10.1002/qj.359.

Omrani, N.-E., N. S. Keenlyside, J. Bader, and E. Manzini, 2014: Stratosphere key for wintertime atmospheric response to warm Atlantic decadal conditions. Climate Dyn., 42, 649-663, doi:10.1007/s00382-013-1860-3

Peings, Y., and G. Magnusdottir, 2014: Response of the wintertime Northern Hemisphere atmospheric circulation to current and projected Arctic sea ice decline: A numerical study with CAM5. J. Climate, 27, 244-264, doi:10.1175/ JCLI-D-13-00272.1.

Polvani, L. M., and D. W. Waugh, 2004: Upward wave activity flux as precursor to extreme stratospheric events and subsequent anomalous surface weather regimes. J. Climate, 17, 3548-3554, doi:10.1175/1520-0442(2004)017<3548:UWAFAA > 2.0.CO;2.

Richter, J. H., F. Sassi, and R. R. Garcia, 2010: Toward a physically based gravity wave source parameterization in a general circulation model. J. Atmos. Sci., 67, 136-156, doi:10.1175/ 2009JAS3112.1.

Sassi, F., R. R. Garcia, D. Marsh, and K. W. Hoppel, 2010: The role of the middle atmosphere in simulations of the troposphere during Northern Hemisphere winter: Differences between high- and low-top models. J. Atmos. Sci., 67, 3048-3064, doi:10.1175/2010JAS3255.1.

Schneider, T., T. Bischoff, and H. Płotka, 2015: Physics of changes in synoptic midlatitude temperature variability. J. Climate, $\mathbf{2 8}$, 2312-2331, doi:10.1175/JCLI-D-14-00632.1.

Scinocca, J. F., M. C. Reader, D. A. Plummer, M. Sigmond, P. J. Kushner, T. G. Shepherd, and R. Ravishankara, 2009: Impact of sudden Arctic sea-ice loss on stratospheric polar ozone 
recovery. Geophys. Res. Lett., 36, L24701, doi:10.1029/ 2009GL041239.

Screen, J. A., 2014: Arctic amplification decreases temperature variance in northern mid- to high-latitudes. Nat. Climate Change, 4, 577-582, doi:10.1038/nclimate2268.

— , and I. Simmonds, 2010: The central role of diminishing sea ice in recent Arctic temperature amplification. Nature, 464, 13341337, doi:10.1038/nature09051.

_ , and _ 2013: Caution needed when linking weather extremes to amplified planetary waves. Proc. Natl. Acad. Sci. USA, 110, E2327, doi:10.1073/pnas.1304867110.

— _ _ C. Deser, and R. Tomas, 2013: The atmospheric response to three decades of observed Arctic sea ice loss. J. Climate, 26, 1230-1248, doi:10.1175/JCLI-D-12-00063.1.

— C. Deser, and L. Sun, 2015: Reduced risk of North American cold extremes due to continued Arctic sea ice loss. Bull. Amer. Meteor. Soc., doi:10.1175/BAMS-D-14-00185.1, in press.

Shaw, T. A., and J. Perlwitz, 2010: The impact of stratospheric model configuration on planetary- scale waves in Northern Hemisphere winter. J. Climate, 23, 3369-3389, doi:10.1175/ 2010JCLI3438.1.

,-- , and O. Weiner, 2014: Troposphere-stratosphere coupling: Links to North Atlantic weather and climate, including their representation in CMIP5 models. J. Geophys. Res. Atmos., 119, 5864-5880, doi:10.1002/2013JD021191.

Sigmond, M., and J. F. Scinocca, 2010: The influence of basic state on the Northern Hemisphere circulation response to climate change. J. Climate, 23, 1434-1446, doi:10.1175/ 2009JCLI3167.1. and P. J. Kushner, 2008: Impact of the stratosphere on tropospheric climate change. Geophys. Res. Lett., 35, L12706, doi:10.1029/2008GL033573.

Smith, K. L., and P. J. Kushner, 2012: Linear interference and the initiation of extratropical stratosphere-troposphere interactions. J. Geophys. Res., 117, D13107, doi:10.1029/2012JD017587.

Stroeve, J. C., V. Kattsov, A. P. Barrett, M. Serreze, T. Pavlova, M. Holland, and W. N. Meier, 2012: Trends in Arctic sea ice extent from CMIP5, CMIP3 and observations. Geophys. Res. Lett., 39, L16502, doi:10.1029/2012GL052676.

Sun, L., C. Deser, L. M. Polvani, and R. Tomas, 2014: Influence of projected Arctic sea ice loss on polar stratospheric ozone and circulation in spring. Environ. Res. Lett., 9, 084016, doi:10.1088/1748-9326/9/8/084016.

Taguchi, M., and D. L. Hartmann, 2006: Increased occurrence of stratospheric sudden warmings during El Niño as simulated by WACCM. J. Climate, 19, 324-332, doi:10.1175/JCLI3655.1.

Thompson, D. W. J., and J. M. Wallace, 2000: Annular modes in the extratropical circulation. Part I: Month-to-month variability. J. Climate, 13, 1000-1016, doi:10.1175/1520-0442(2000)013<1000: AMITEC $>2.0 . \mathrm{CO} ; 2$.

Watson, P. A., and L. J. Gray, 2014: How does the quasi-biennial oscillation affect the stratospheric polar vortex? J. Atmos. Sci., 71, 391-409, doi:10.1175/JAS-D-13-096.1.

Wu, Q., and X. Zhang, 2010: Observed forcing-feedback processes between Northern Hemisphere atmospheric circulation and Arctic sea ice coverage. J. Geophys. Res., 115, D14119, doi:10.1029/2009JD013574. 